\title{
Exposure to airborne gold nanoparticles: a review of current toxicological data on the respiratory tract
}

\author{
Barbara De Berardis • Magda Marchetti • \\ Anna Risuglia • Federica Ietto • Carla Fanizza • \\ Fabiana Superti $($ D
}

Received: 20 March 2020 / Accepted: 28 July 2020

(C) The Author(s) 2020

\begin{abstract}
In recent years, the introduction of innovative low-cost and large-scale processes for the synthesis of engineered nanoparticles with at least one dimension less than $100 \mathrm{~nm}$ has led to countless useful and extensive applications. In this context, gold nanoparticles stimulated a growing interest, due to their peculiar characteristics such as ease of synthesis, chemical stability
\end{abstract}

Barbara De Berardis and Magda Marchetti contributed equally to this work.

B. De Berardis · M. Marchetti · F. Superti $(\bowtie)$

National Centre for Innovative Technologies in Public Health,

National Institute of Health, Viale Regina Elena 299,

00161 Rome, Italy

e-mail: fabiana.superti@iss.it

B. De Berardis

e-mail: barbara.deberardis@iss.it

M. Marchetti

e-mail: magda.marchetti@iss.it

\section{A. Risuglia $\cdot$ F. Ietto $\cdot$ C. Fanizza}

Department of Technological Innovations and Safety of Plants, Products and Anthropic Settlements, INAIL, Via R. Ferruzzi

38-40, 00143 Rome, Italy

\author{
A. Risuglia \\ e-mail: a.risuglia@inail.it \\ F. Ietto \\ e-mail: f.ietto@inail.it \\ C. Fanizza \\ e-mail: c.fanizza@inail.it
}

and optical properties. This stirred the development of numerous applications especially in the biomedical field. Exposure of manufacturers and consumers to industrial products containing nanoparticles poses a potential risk to human health and the environment. Despite this, the precise mechanisms of nanomaterial toxicity have not yet been fully elucidated. It is well known that the three main routes of exposure to nanomaterials are by inhalation, ingestion and through the skin, with inhalation being the most common route of exposure to NPs in the workplace. To provide a complete picture of the impact of inhaled gold nanoparticles on human health, in this article, we review the current knowledge about the physico-chemical characteristics of this nanomaterial, in the size range of 1-100 nm, and its toxicity for pulmonary structures both in vitro and in vivo. Studies comparing the toxic effect of NPs larger than $100 \mathrm{~nm}$ (up to $250 \mathrm{~nm}$ ) are also discussed.

Keywords Nanomaterials · Gold nanoparticles · Physico-chemical properties $\cdot$ Respiratory exposure . In vitro toxicity · In vivo toxicity · Environmental and health effects

\section{Introduction}

Nanotechnology enabled the development of engineered materials at the nanometre scale with specific properties related to their size, morphology and surface reactivity. Due to their peculiar physico-chemical characteristics, nanoparticles raised great interest for 
their potential applications both in consumer products and in the biomedical field. Gold nanoparticles (AuNPs) are attractive in several areas such as electronics, sensors (Han et al. 2015a), solar cells (Chen et al. 2015) and catalysis (Nita et al. 2016). They are also used in cosmetics and as dietary supplements.

According to the inventory of the Woodrow Wilson International Center for Scholars, products containing AuNPs rank sixth among nanotechnology consumer products (Vance et al. 2015). In particular, the increased interest in AuNP biomedical applications is due to their interesting optical properties derived from their unique interaction with light. The conduction electrons present on the surface of AuNPs are mobile and create oscillations that propagate as waves, called surface plasmons. When the wave vector of incident light is coupled with the wave vector of the surface plasmons, a collective coherent oscillation of conduction electrons occurs, called surface plasmon resonance (SPR). The plasmon resonance can either radiate light, a process used in optical and imaging fields, or it can be absorbed and converted to heat, a phenomenon used in photothermal cancer therapy (Bodelón et al. 2017). All these properties, together with easy surface functionalisation, make AuNPs versatile platforms for diagnosis, therapy, drug delivery and tissue engineering. Recently, in order to reduce the risk associated with systemic exposure, the use of inhaled AuNPs as drug carrier and radiosensitiser (Hamzawy et al. 2017; Hao et al. 2015) has been investigated.

The increasing use of AuNPs in industrial processes and biomedical research involves the exposure of a higher number of workers. Although no exact data are available on the number of workers exposed to NPs, in 2012, the European Commission declared about 400,000 workers involved in the nanotechnology sector in the European Union alone (EEC 2012), with 6 million workers estimated to be potentially exposed in 2020 (Roco 2011). Research laboratories using engineered nanomaterials (ENMs) represent the workplaces with the highest potential exposure (NIOSH 2012). Worker exposure to AuNPs might occur during production (synthesis, harvesting, dumping, mixing, reactor cleaning, transferring), preparation of suspensions or incorporation into products.

Due to the growing number of workers exposed to NPs, measurement strategies, techniques and methods to evaluate exposure in workplaces have been developed (Brenner et al. 2016; Garcia et al. 2017; Asbach et al. 2017).
Currently, there are no occupational exposure standards for NPs. Moreover, the choice of the most appropriate metric to evaluate exposure levels to NPs is still widely debated and complicated due to their high numbers and negligible masses. The US National Institute for Occupational Safety and Health (NIOSH) proposed particle number concentration as an alternative metric to the traditional mass concentration (Methner et al. 2010).

Several unofficial occupational exposure limits (OELs) have been recommended by national organisations in the UK, Germany, the Netherlands, the USA and Australia. These organisations categorised NPs into five groups: insoluble fibre-like NPs with high aspect ratio; biopersistent NPs with density lower than $6000 \mathrm{~kg} / \mathrm{m}^{3}$; biopersistent NPs with density higher than $6000 \mathrm{~kg} / \mathrm{m}^{3}$; NPs already classified in their larger size as carcinogenetic, mutagenic, asthmagenic or reproductive toxin; and soluble NPs. Cerium oxide, gold, iron, iron oxide, silver, cobalt, lanthane, lead and antimony oxide belong to the third group. For NPs in this group, which includes AuNPs, an OEL equal to $2 \times 10^{4}$ particles $/ \mathrm{cm}^{3}$ has been proposed by the UK, Germany and the Netherlands (van Broekhuizen et al. 2012).

Very few data are available on AuNP exposure in the workplaces. Zimmermann et al. (2012) showed that AuNP release can occur during the maintenance and the cleanout of deposition equipment. In a case study on AuNP exposure assessment in a pilot-scale facility, the authors measured particle emission during the preparation and the synthesis and post-synthesis phases of $14 \mathrm{~nm}$ AuNPs, using a combination of particle number concentration counters and filter-based air sampling for particle characterisation. They found a significant increase of particle number concentration up to 10,295 particles $/ \mathrm{cm}^{3}$ compared to background, below the proposed OEL for AuNPs, in the size range between 7 and $300 \mathrm{~nm}$ during the synthesis phase, with a peak in the range 7-35 nm (OECD 2016a). This does not mean that exposure to AuNPs of workers, engaged in industrial processes or laboratory activities, is not a potential health risk. In fact, they are subjected to repeated exposures that may involve a risk, especially for workers with lung and cardiovascular diseases, as already highlighted for exposure to airborne ultrafine particles (Miller et al. 2012).

Inhalation is one of the main routes of exposure to NPs and many studies showed how NP exposure may impact on pulmonary response; however, only few investigations on pulmonary toxicity of AuNPs have been 
performed. In particular, several toxicological studies and biodistribution of AuNPs after intravenous, oral and peritoneal administration are available in the literature (De Jong et al. 2008; Balasubramanian et al. 2010; Zhang et al. 2010; Schleh et al. 2012; Rambanapasi et al. 2016), while there is a lack of information about inhalation toxicity, especially as in vivo studies. Most of these investigations have used intratracheal instillation to deliver AuNPs to the lung and very few studies have been performed with a whole-body inhalation chamber (Semmler-Behnke et al. 2008; Jacobsen et al. 2009; Sadauskas et al. 2009; Lipka et al. 2010; Balasubramanian et al. 2013; Han et al. 2015b; Sung et al. 2011).

In this manuscript, we illustrate the state of the art on AuNP in vitro and in vivo toxicity due to inhalation exposure. We also review the principal methods for AuNP synthesis and surface functionalisation and the most important shapes and types of functionalisation used in consumer products and in biomedical research, as well as the principal techniques used to determine their physico-chemical properties. The aim of this review is to analyse in-depth the literature available to detect strengths and possible deficiencies to identify one or more ideal approaches for the risk assessment of inhalation exposure to AuNPs.

\section{Gold nanoparticle synthesis, shape and functionalisation}

Gold nanoparticle synthesis and nanoparticle solution stabilisation

The methods for AuNP synthesis can be divided into physical, chemical and biological. The physical method consists in laser ablation of a solid target placed in a liquid medium (Sylvestre et al. 2004), whereas chemical synthesis of metal NPs consists in the reduction of metal salts. The most used chemical methods to synthesise AuNPs are due to Turkevich et al. (1951) and Brust et al. (1994). Using the Turkevich method, AuNPstabilised suspensions of negatively charged and spherical shape with sizes between 15 and $100 \mathrm{~nm}$ are synthesised, depending on the ratio of sodium citrate to $\mathrm{Au}$. As sodium citrate concentration increases, the AuNP diameter decreases (Nicol et al. 2015). The BrustSchiffrin method is used to synthetise thiolate- stabilised AuNPs with diameter less than $5 \mathrm{~nm}$ (Zhao et al. 2013).

For the biological synthesis, several procedures are available to produce NPs with different sizes, shapes and surface properties (Zhao et al. 2013). The synthesis consists in the incubation, in an appropriate medium, of metal salt solution with a biological agent, as reducing agent. The biological agent used is part of a bacterial, fungal, viral or plant system, like enzymes, biomolecules, terpenoids, phenols and alkaloids. Plants or algae are the most used systems for the production of NPs because they are efficient, safer and less timeconsuming (Chugh et al. 2018). Shape, size and properties of NPs can be modified by altering $\mathrm{pH}$, temperature, pressure, time and biological reducing agent (Chugh et al. 2018). The main advantage of green synthesis is the production of pure NPs, whereas NPs obtained by chemical methods are contaminated by products used during the process. Once the NP synthesis process is complete, it is necessary to perform a stabilisation step of the obtained NP solution, with a dispersant layer of appropriate thickness. This is needed in order to avoid agglomeration and aggregation phenomena and to allow their effective application in various fields. Two methods can be used to stabilise the solution: electrostatic stabilisation, leveraging the same charge on the NP surface, causing the repulsion of particles; or steric stabilisation, using a polymeric coating that does not allow the NPs to reach the minimum distance for which the van der Waal forces can cause their aggregation.

Shape of gold nanoparticles in biomedical applications

The shape and size of AuNPs can be finely tuned and easily controlled during the synthesis process in the range $1-150 \mathrm{~nm}$ in order to obtain NPs with specific chemical, electrical and optical properties (Jain et al. 2008) used in different fields of nanotechnology applications.

AuNPs with different shapes, as nanospheres, nanorods, nanostars, nanocages, nanoshells, hollow nanoshells and nanomatryoshkas, have been synthetised (Fig. 1).

Each of these shapes exhibits a specific maximum excitation of surface electrons and a unique conversion efficiency of light to heat, depending on size and aggregation state. Au nanorods are particles with a cylindrical shape and a length to diameter ratio (aspect ratio) greater 
Fig. 1 Schematic representation of different shapes of AuNPs
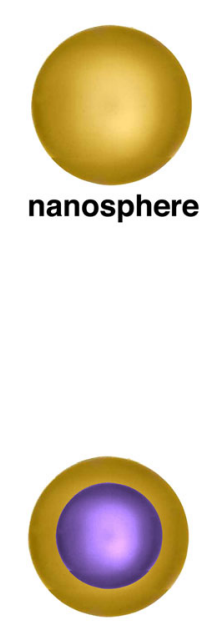

nanoshell than 1 . The sizes of nanorods have a strong influence on the scattering efficiency of NPs because the longitudinal SPR along the long axis of these NPs depends strongly on aspect ratio. It has been shown (Lohse and Murphy 2013) that larger Au nanorods scatter light more efficiently at longitudinal SPR than smaller Au nanorods. As a result, larger Au nanorods can find better applications in the field of optical imaging, whereas smaller $\mathrm{Au}$ nanorods can be used in photothermal therapy due to their higher absorption efficiency (Lohse and Murphy 2013). Au nanostars exhibit a spherical core with multiple sharp edges. These protruding tips allow to obtain a red shift in the absorption spectra of AuNPs, used in photothermal therapy (Vines et al. 2019). Au nanocages are nanostructures that exhibit hollow interiors or porous walls. Due to this morphology, these NPs have gained an increasing interest in biomedical applications, as this morphology allows to load drugs and theranostic agents in the cavity of NPs (Kohout et al. 2018). Au nanoshells have a layer of gold surrounding a core made of silica that causes a red shift of the characteristic plasmon absorption spectrum of gold to the NIR region of the electromagnetic spectrum. The plasmon resonance frequency is tunable by altering the core to shell ratio. These NPs are biologically non-reactive, particularly if coated with a layer of polyethylene glycol (PEG). Au hollow nanoshells show a thin outer Au shell and a

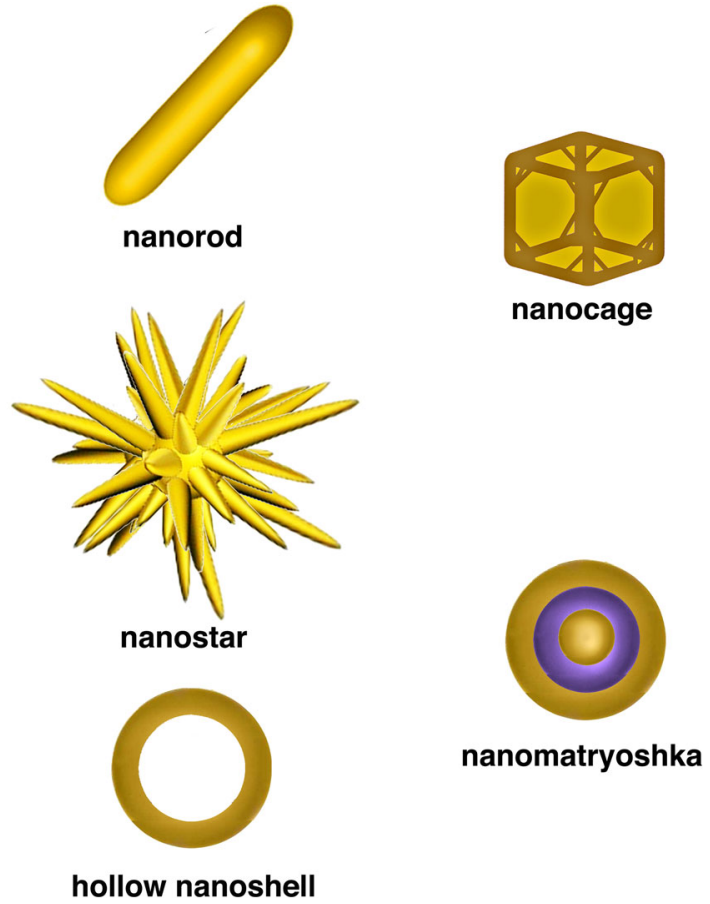

hollow core, used for drug delivery (Vines et al. 2019). Au nanomatryoshkas have a gold core coupled to a thin silica shell with a gold epilayer around them. In this way, a strong coupling between the plasmons of the gold core and the shell is established, which makes the AuNPs intensely photothermically activable. Their plasmon resonance is tunable to NIR wavelengths by altering the relative thicknesses of the core, the shell and the epilayer (Kaur et al. 2016).

\section{Functionalisation of gold nanoparticles}

The biomedical applications of AuNPs require a modification of their surface to achieve high efficiency and limit the treatment toxicity. AuNPs possess tunable surface chemistry so that several functional groups can be conjugated on their surface. Taking advantage of the ability of AuNP to bind thiol and amine groups, together with SPR, their surface can be modified in order to enhance cellular uptake and achieve more targeted therapy (Nicol et al. 2015; Vines et al. 2019). By replacing the stabilising surfactant surrounding AuNP surface with PEG, a long circulation can be achieved (Choi et al. 2003). Several functionalised groups can be attached to NPs, including low molecular weight ligands, peptides, proteins, polysaccharides, polyunsaturated and saturated fatty acids, DNA, antibodies, plasmids 
and siRNA. For conjugation of antibodies or functionalised groups to AuNPs, both covalent and non-covalent immobilisation modes can be used (Fig. 2). These techniques take advantage of the physical and chemical interactions between AuNPs and antibodies or other molecules. The non-covalent mode is based on two types of physical interactions: the electrostatic attraction between positively charged groups in antibodies and the AuNP negatively charged surface and the hydrophobic attraction between the AuNP surface and the antibody. The main limitations of this method are that it is suitable only for appropriately charged ligands, and the binding is influenced by $\mathrm{pH}$ changes (Nicol et al. 2015). The covalent mode is based on the dative binding between the Au conducting electrons and amino acid sulphur atoms of the antibody and the chemical interactions between antibodies and AuNPs. These interactions are achieved by chemisorption via thiol derivatives, through the use of bifunctional linkers and through the use of adapter molecules like avidin and biotin (Jazayeri et al. 2016; Kumar et al. 2008). Using these techniques, AuNPs can be cofunctionalised with different ligands in the form of mixed monolayer like PEG and peptides, PEG and fluorescing dye, or PEG and heavy metal atoms (Kumar et al. 2012; Huang et al. 2010; Kirui et al.

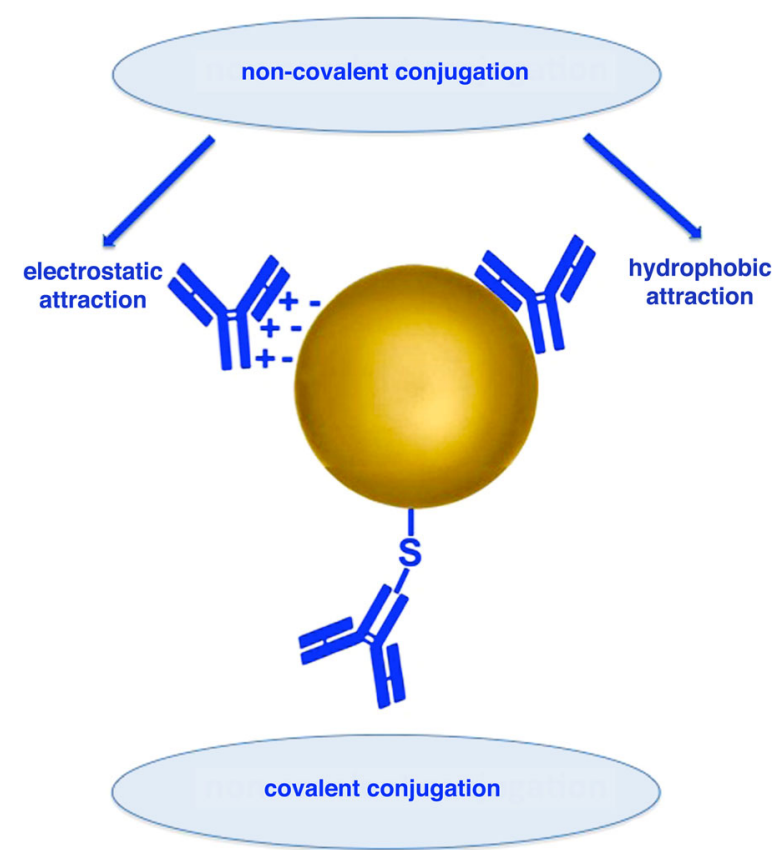

Fig. 2 Non-covalent and covalent conjugation modes of antibodies to AuNPs: schematic representation
2010). An alternative approach to attach a ligand on AuNP surface consists in the use of a linker molecule, like a polymer chain, in order to achieve AuNP stability. At the other end of the chain, the functional ligand is attached and it is available for biological interaction (Nicol et al. 2015).

\section{Characterisation of gold nanoparticles}

The increasing number of NP-based products is a matter of concern among the scientific community and international bodies, such as the Organisation for Economic Co-operation and Development (OECD), European Food Safety Authority (EFSA) and Scientific Committee on Emerging and Newly Identified Health Risks (SCENIHR), due to the potential human health effects of NPs, related to their increased surface chemical reactivity. Although the mechanisms underlying NP toxicity have not yet been fully elucidated, regarding AuNPs, toxicological data point out that the main characteristics involved in AuNP toxicity mechanisms are primary size, shape, specific surface area, surface charge and surface chemistry. As expected, the size plays an important role in the cellular uptake process (Chithrani et al. 2006; Arnida et al. 2010). The major pathway for cellular uptake of most AuNPs is receptor-mediated or absorptive endocytosis. This mechanism is probably enabled by the protein layer that coats the NP surface in the presence of biological fluids: the protein corona (Chithrani et al. 2006; Arnida et al. 2010; Chithrani et al. 2010; Chithrani 2010; Ng et al. 2015). However, AuNPs smaller than $10 \mathrm{~nm}$ pass into cells directly through the cell membrane and enter the cell nucleus probably because they can pass through the nuclear pores (Chithrani et al. 2006; Huo et al. 2014; Pan et al. 2007). Also, in vivo, a size-dependent effect on the translocation of AuNPs to other parts of the body has been observed (Sonavane et al. 2008; Hirn et al. 2011). Chithrani et al. (2006) showed that single AuNPs of $50 \mathrm{~nm}$ enter cells more efficiently than $14 \mathrm{~nm}$ AuNPs of the same chemical composition. It is difficult to draw meaningful conclusions about the relationship between size and cytotoxicity as several studies showed a size-dependent toxicity effect of AuNPs (Pan et al. 2007; Senut et al. 2016), while others consider more important the contribution of concentration, surface modification or shape (Chithrani et al. 2006; Mironava et al. 2010; Pan et al. 2009; Wang et al. 2013). Chithrani et al. (2006) have 
shown a role of NP shape and surface chemistry in cellular uptake and cytotoxicity induction. Spherical AuNPs with size between 10 and $100 \mathrm{~nm}$ showed higher cellular uptake than $\mathrm{Au}$ nanorods in the same size range. Moreover, rod-shaped AuNPs with aspect ratio (1:3) showed cellular uptake greater than NPs with aspect ratio (1:5) (Chithrani et al. 2006). Wang et al. (2013) compared the in vitro and in vivo capabilities of $\mathrm{Au}$ nanohexapods, nanorods and nanocages for photothermal cancer treatment and found that $\mathrm{Au}$ nanohexapods exhibit the highest cellular uptake and the lowest cytotoxicity in vitro. Wang et al. (2016) analysed the impact of AuNP shape on the cytotoxicity induction in a zebrafish model showing that spherical particles are more toxic than rod- and polyhedronshaped NPs. In contrast, Karakoçak et al. (2016) showed that nanorods are more cytotoxic than spherical NPs in a retinal pigment epithelial (ARPE-19) cell line. Finally, Wan et al. (2015) demonstrated that NP cytotoxic effect is related to their surface chemistry but not to their aspect ratio, whereas Qiu et al. (2010) did not exclude a role to this characteristic. Surface charge also plays an important role in NP cellular uptake due to the electrostatic interactions between the negatively charged cell membrane glycoproteins and the NPs. An uptake mechanism different from endocytosis has been demonstrated for ligand-free positively charged AuNPs, and diffusion has been proposed as a possible entry pathway (Taylor et al. 2010). It has been demonstrated that the uptake efficiency of the positively charged AuNPs is greater than the neutral or negatively charged ones (Hauck et al. 2008; Alkilany et al. 2009; Cho et al. 2009; Liang et al. 2010; Liu et al. 2013). Moreover, the cells take up negatively charged AuNPs with greater efficiency than the neutral AuNPs, most probably because of a better binding with membrane surface proteins (Liang et al. 2010). Positively charged AuNPs not only penetrate more effectively the cell membrane but also show higher toxicity compared to negatively NPs (Liu et al. 2013). Finally, it has been shown that the charge of AuNPs plays a greater role in the uptake of AuNPs with respect to their size (Liang et al. 2010). All these data available in the literature show that numerous physicochemical properties of NPs are simultaneously involved in NP-cell interactions. Therefore, it is essential to study in-depth NP characteristics in order to identify and clarify the mechanism of their potential toxicity.

NP characterisation is complex and the OECD and other international bodies have provided a list of analytical techniques to be used for each parameter of interest in NP characterisation (OECD 2016b; ECHA 2017; EFSA 2018). Multiple techniques should be used where possible in order to better understand NP properties and NP-cell interaction mechanisms. Examples of analytical techniques for the most important characteristics of NPs are shown in Table 1.

Two types of NP samples are used in the in vivo study for inhalation exposure: NP suspensions and NP aerosol. The principal techniques for the characterisation of AuNP powders and AuNP suspension as well as AuNP aerosol are described below.

Principal techniques for the characterisation of AuNP powders and suspensions

\section{Size/size distribution evaluation}

In recent years, various analytical techniques have been developed for determining the size and size distribution of ENMs, based on physical phenomena observed in particle interaction or on nanometric scale forces. Since there is no single analytical technique capable to determine the size distribution in the range $1-100 \mathrm{~nm}$ satisfactorily, the Working Party of Manufactured Nanomaterial of OECD, EFSA and other international bodies declared that different techniques should be used for NP size determination. The choice of technique depends on the state in which ENMs occur, such as in powder form, dispersed in a liquid or incorporated in a solid material or in a matrix. One of the techniques used to determine both size and size distribution and therefore to identify the NPs in a consumer product must be electron microscopy (EM), such as transmission electron microscopy (TEM) and scanning electron microscopy (SEM). The main advantage of EM consists in the determination of size, shape and crystal structure of each individual particle. Moreover, unlike other techniques, it allows to characterise samples containing mixtures of NPs with different sizes and shapes. Finally, if combined with an energy-dispersive X-ray spectrometer, it allows to determine ENM chemical composition (De Berardis et al. 2010). The main limitation is that EM does not permit a quantitative analysis of the sample and requires long analysis times and experienced operators. In addition, this technique requires sample preparations to remove any solvent or liquid medium for NP dispersions leading to artefacts. 
Table 1 Examples of analytical techniques for the most important characteristics of NPs

\begin{tabular}{|c|c|c|c|}
\hline NP properties & Techniques/principles & Main disadvantages & Available guidance $^{\mathrm{a}}$ \\
\hline \multirow[t]{4}{*}{ Size/size distribution } & $\begin{array}{l}\text { SEM: secondary electrons } \\
\text { (SE) or backscattered } \\
\text { electrons (BSE) to form } \\
\text { NP image }\end{array}$ & $\begin{array}{l}\text { High vacuum condition required } \\
\text { Conductive material coating required } \\
\text { Operator experience dependent } \\
\text { Long analysis times } \\
\text { Possible artefacts due to sample preparation }\end{array}$ & $\begin{array}{l}\text { ISO/WD } 19749 \\
\text { ISO 13322-1 }\end{array}$ \\
\hline & $\begin{array}{l}\text { TEM: transmitted electrons } \\
\text { through the sample to } \\
\text { form the image }\end{array}$ & $\begin{array}{l}\text { High vacuum condition required } \\
\text { High voltage electron beam } \\
\text { Extremely thin sample to create image } \\
\text { Operator experience dependent } \\
\text { Long analysis times }\end{array}$ & $\begin{array}{l}\text { ISO/WD } 21363 \\
\text { ISO } 13322-1\end{array}$ \\
\hline & $\begin{array}{l}\text { DLS: fluctuations in the } \\
\text { intensity of scattered } \\
\text { light caused by Brownian } \\
\text { motion of particles }\end{array}$ & $\begin{array}{l}\text { Scattering intensity dependence by the } \\
\text { sixth power of the NP radius leading to } \\
\text { misleading results for suspension with } \\
\text { NPs of different sizes } \\
\text { Limitations in polydisperse suspensions } \\
\text { Assumption of spherical shape NPs } \\
\text { Misleading results for non-spherical NP } \\
\text { suspensions }\end{array}$ & ISO 22412 \\
\hline & $\begin{array}{l}\text { PTA: observation and } \\
\text { registration on a video } \\
\text { camera of light scattered } \\
\text { by single NPs or NP } \\
\text { agglomerates }\end{array}$ & Difficult detection of NPs smaller than $20 \mathrm{~nm}$ & ISO 19430 \\
\hline \multirow[t]{2}{*}{ Shape } & $\begin{array}{l}\text { Analysis systems of SE } \\
\text { images obtained by SEM }\end{array}$ & $\begin{array}{l}\text { Operator experience dependent } \\
\text { Long analysis times } \\
\text { Possible artefacts due to sample preparation }\end{array}$ & ISO/WD19749 ISO 13322-1 \\
\hline & $\begin{array}{l}\text { TEM: analysis systems of } \\
\text { image obtained by TEM }\end{array}$ & $\begin{array}{l}\text { Extremely thin sample to create image } \\
\text { Operator experience dependent } \\
\text { Long analysis times }\end{array}$ & $\begin{array}{l}\text { ISO/WD } 21363 \\
\text { ISO } 13322-1\end{array}$ \\
\hline Surface area & $\begin{array}{l}\text { BET: adsorption isotherm } \\
\text { theory to calculate } \\
\text { surface area }\end{array}$ & $\begin{array}{l}\text { Dry solid sample required } \\
\text { Only for NPs that do not absorb gas } \\
\text { Limitation for porous NP application }\end{array}$ & $\begin{array}{l}\text { ISO } 9277 \\
\text { ISO } 15901-2 /-3 \text { ISO } 18757\end{array}$ \\
\hline Surface charge & $\begin{array}{l}\text { Zeta potential: electrophoretic } \\
\text { light scattering }\end{array}$ & $\begin{array}{l}\text { Dependent on } \mathrm{pH} \text { suspension } \\
\text { Particle concentration } \\
\text { Non-suitable for fluorescing samples }\end{array}$ & ISO 13099 series \\
\hline Chemical composition & $\begin{array}{l}\text { EDX: characteristic X-ray } \\
\text { emitted by sample upon } \\
\text { interaction with an incident } \\
\text { electron beam }\end{array}$ & $\begin{array}{l}\text { High vacuum condition required } \\
\text { Conductive material coating required } \\
\text { Semi-quantitative analysis } \\
\text { Detection of element with } Z>5 \\
\text { Thermal damage to the sample } \\
\text { Poor accuracy of semi-quantitative } \\
\quad \text { analysis for element at low concentrations }\end{array}$ & ISO 22489 \\
\hline \multirow[t]{2}{*}{ Surface chemistry } & $\begin{array}{l}\text { XPS: kinetic energy } \\
\text { measurements of electrons } \\
\text { escaped from sample } \\
\text { surface upon incident } \\
\text { X-ray beam }\end{array}$ & $\begin{array}{l}\text { High vacuum condition required } \\
\text { Suitable only for elemental composition } \\
\text { of a } 0-10 \text {-nm surface layer } \\
\text { Long collection time of acquisition }\end{array}$ & $\begin{array}{l}\text { ISO/TR } 14187 \\
\text { ISO } 18118\end{array}$ \\
\hline & $\begin{array}{l}\text { Raman: measurement of } \\
\text { vibrational energy levels } \\
\text { associated with the chemical } \\
\text { bonds in the sample }\end{array}$ & $\begin{array}{l}\text { Interference of fluorescence } \\
\text { Extremely small cross section } \\
\text { Intense laser excitation } \\
\text { Large amount of sample to provide } \\
\quad \text { sufficient signals }\end{array}$ & NA \\
\hline
\end{tabular}

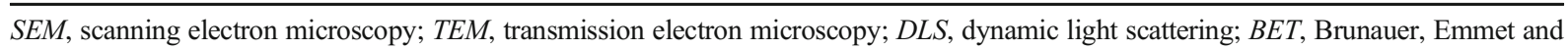
Teller; $E D X$, energy-dispersive X-ray spectroscopy; XPS, X-ray photoelectron spectroscopy; $N A$, not available

${ }^{a}$ Guidance available on "Guidance on risk assessment of the application of nanoscience and nanotechnologies in the food and feed chain: Part 1, human and animal health" (EFSA 2018) 
Other methods widely used to determine the size and size distribution of NPs are based on laser light scattering techniques, such as dynamic light scattering (DLS) or particle tracking analysis (PTA) (Calzolai et al. 2012). DLS enables a rapid in situ characterisation of size and size distribution of particles dispersed in a liquid, illuminating an optical cell containing a dilute solution of particles with a laser light. The hydrodynamic diameter is calculated by measuring fluctuations in the intensity of scattered light caused by Brownian motion. DLS also provides a number indicating the polydispersity of the particle population, called polydispersity index (PDI). This technique is ideal for monodispersed samples $(\mathrm{PDI}<0.1)$ containing spherical particles. When particles with different sizes or nonspherical particles are present in the sample, DLS can give misleading results due to scattering intensity dependence on the 6th power of radius (Calzolai et al. 2012) and on the assumption of spherical shape for the determination of hydrodynamic diameter. In the case of non-spherical particles, DLS cannot provide any reliable measure of size without prior knowledge of particle shape data that can only be determined by EM. The PTA observes and records, on a highly sensitive video camera, the rapid movement of each particle or aggregate in a suspension illuminated by a laser source. The hydrodynamic diameter of each particle is calculated through the Stokes-Einstein equation. Unlike DLS, PTA calculates particle size on a particle-by-particle basis and is highly sensitive since it detects particles at concentrations as low as $10^{6}$ particles $/ \mathrm{cm}^{3}$. The biggest disadvantage of this technique is the limitation on the lowest particle size that can be detected. As the light scattering of particles in solutions depends not only on the refractive indices of the material and liquid but also on the particle size, it is difficult to detect particles smaller than $20 \mathrm{~nm}$, except for those with a high refractive index such as $\mathrm{Au}$ (Calzolai et al. 2012).

\section{Shape evaluation}

NP shape is variable, and to characterise this feature, shape factors such as sphericity, circularity, aspect ratio, convexity and fractal dimension are used (ECHA 2017).

Particle shape is usually determined by EM, the only technique able to identify the presence of particles with different morphologies in a sample. It includes many qualitative and semi-quantitative techniques, based on image-analysis systems to investigate the morphology and the aggregation state. Two different morphologies of commercial AuNPs (Nanocs Inc., USA) are shown in Fig. 3: spherical $(40 \mathrm{~nm})$ and rod-like shape $(10 \times$ $60 \mathrm{~nm}$ ). NPs with irregular shape were observed in the Au nanorod sample.

\section{Specific surface area evaluation}

The specific surface area is the area of the exposed surface of a certain amount of material divided by its mass. It plays an important role in the physical and chemical interactions because molecules detached from the surface or located at the surface of the ENMs interact with the biological fluids and tissue. Jacobsen et al. (2009) in a study on pulmonary toxicity of intratracheally instilled AuNP in the lungs of mice reported that NPs with high specific surface area exhibited higher reactivity than particles with low specific surface area. This characteristic determines the surface charge in functionalised NPs and has direct consequences on NP agglomeration and NP-cell interactions.

The most common technique for measurement of the surface area of particles is by gas absorption measurements using Brunauer, Emmet and Teller (BET) adsorption isotherm theory (Brunauer et al. 1938). Nitrogen is the most used, but many other gases such as argon, carbon dioxide or krypton are also employed. The main disadvantages of this technique are in its application only to dry ENMs and in the assumption of a monodispersed spherical sample. Moreover, this technique is not optimal for porous NPs (OECD 2016b).

\section{Surface charge evaluation}

In order to determine the surface charge, the surface potential is evaluated by measuring the zeta potential (OECD 2016b; ECHA 2017; EFSA 2018). This is defined as the potential difference between the NP dispersion medium and the stationary double ionic layer of fluid attached to NPs. Measurement of zeta potential gives information on the stability of NP suspension. High positive $(>+30 \mathrm{mV})$ or negative $(<-30 \mathrm{mV})$ values of zeta potential indicate good physical stability of NP suspension due to electrostatic repulsion of individual particles, whereas low values can lead to NP agglomeration and flocculation due to the van der Waals attractive forces. 

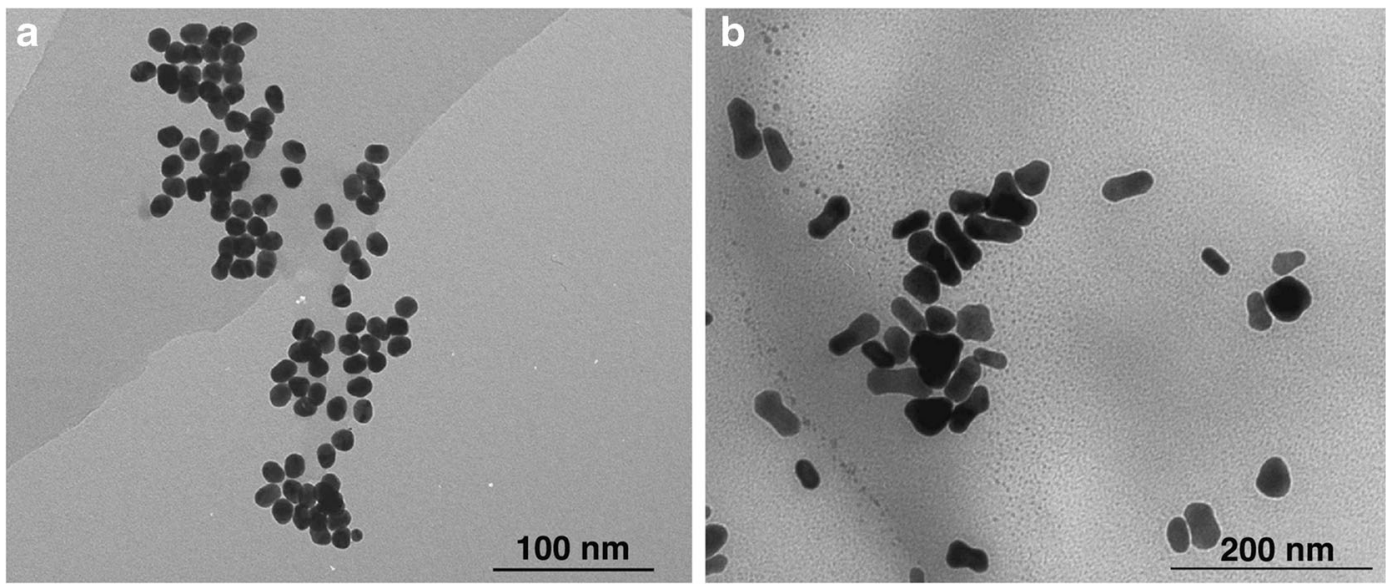

Fig. 3 TEM images of a spherical AuNPs and b Au nanorods

\section{Surface chemistry evaluation}

The expression surface chemistry includes coatings, functional groups and potential surface reactions of NPs in different media. In most NP applications, it is essential to control the surface chemistry of ENMs; therefore, high sensitivity spectroscopic methods are used and developed to characterise their surface chemistry in order to gain a better insight into the elemental distribution, such as X-ray photoelectron spectroscopy (XPS) and Raman spectroscopy.

XPS is an ultrahigh-vacuum surface analysis technique widely used for the analysis of chemical composition, chemical state and electronic state of the elements on the surface material and for the determination of contaminations or functional group on it. It is based on the ejection of valence electrons (photoelectrons) by atoms from the top 1-10 $\mathrm{nm}$ of the sample when a beam of X-ray irradiates its surface. Since these photoelectrons have energies that are specific for the emitting elements and sensitive for the chemical states of the elements, the energies and the peak intensities in the XPS spectrum give information on elemental composition and on chemical bonding identified on the sample surface.

Raman spectroscopy is based on the detection of radiation scattered from the molecules in a sample when irradiated by a monochromatic light. This analytical technique, providing a characteristic spectrum of the specific vibrations of a molecule, allows the identification of the substance (Smith and Dent 2005). Moreover, it gives information on the structure of molecules and how they interact with that surrounding. Raman spectroscopy is a useful technique to describe the binding interactions of ligand-AuNPs since, unlike other ENMs, AuNPs enhance vibrational Raman bands due to surface plasmon effects (Smith and Dent 2005). XPS and Raman spectroscopy were used to characterise the surface of functionalised AuNPs (Debouttière et al. 2006; Techane et al. 2011; Lam et al. 2014).

\section{Principal techniques for aerosol characterisation}

The aerosol consists of airborne particles with dimensions in the range $10^{-9} \mathrm{~m}$ to $100 \mu \mathrm{m}$ (Kulkarni et al. 2012). Due to their different sizes, these particles behave differently in the air because different physical laws govern their motion. The inertia dominates the motion of particles larger than $0.3-0.5 \mu \mathrm{m}$ that is described by aerodynamic equivalent diameter, while the Brownian motion governs prevalently the motion of particles with the size of a few nanometres. It is described by mobility equivalent diameter, defined as the diameter of a spherical particle with the same velocity (mobility) produced by a unit external electrical force as the particle in question (Kulkarni et al. 2012).

These principles are used in the various tools developed for aerosol characterisation.

There are two distinct categories of measurement techniques to characterise the aerosol; the first is based on the collection of aerosol particles on a substrate, and the second is on in situ, near real-time measurement of aerosol. The first approach allows a deep characterisation of aerosol to determine primary size, morphology, agglomeration and chemical composition of NP sampled in the aerosol. However, its main disadvantages 
consist in that the collection processes may lead to particle modification and the measurements are timeaveraged (Kulkarni et al. 2012). The second approach allows a more limited degree of particle characterisation. In studies to assess the in vivo inhalation toxicity, the second approach is used because it is critical in real-time monitoring of system exposure. The most important characteristics of aerosol are the size distribution and the particle number concentration.

The size distribution of aerosol used in studies to assess the biodistribution of NPs after inhalation exposure ranges between a few nanometres and $1 \mu \mathrm{m}$. Recently, different sensors for size distribution evaluation have been developed, based on the electrical mobility determination. They consist of a corona charger, a mobility classifier and a particle detector. The charged aerosol, via ion-particle collisions by the corona charger, passes into the coaxially cylindrical electrodes of the electrical mobility classifier (Intra and Tippayawong 2007). An electric field, applied between the electrodes, deflects the particles radially outward, and particles having specific mobility are collected. The instrument measures the currents corresponding to the number concentration of particles of a given mobility, related to particle size. A data acquisition system processed the signal currents and the particle mobility diameter is calculated (Intra and Tippayawong 2007). One of the most used aerosol sizer, based on the electrical mobility measurement, is the scanning mobility particle sizer (SMPS). It allows to determine the particle number concentration in the range of 3-1000 nm separating the particles from a polydisperse aerosol in narrow intervals of sizes and counting the particles within that size range by a detector (Flagan 2008). The SMPS scans across a voltage range. For a given applied voltage, particles with higher electrical mobility are collected sooner than those with lower electrical mobility. The smaller the particle diameter and the higher the number of charges, the greater the electrical mobility. The inverse relationship between electrical mobility and particle size allows the determination of aerosol size distribution (Flagan 2008). Therefore, for a given voltage, only particles within a narrow range of electrical mobility diameter are transferred into the condensation particle counter (CPC), where the number concentration of the particles is measured. The particle number concentration that the SMPS can measure is approximately $10^{4}-10^{9}$ particles $/ \mathrm{cm}^{3}$ (Intra and Tippayawong 2007). The software of these instruments allows to calculate the surface area, volume and mass of the particles. The major limitation of these techniques consists in the assumption that all particles measured are spherical, but some aerosols are composed of NP aggregates showing the shape of chains (Shi et al. 2001). Therefore, the electrical mobility analysis tools of this type of aggregates can lead to an incorrect evaluation of these parameters.

Another technique developed to measure the aerosol size distribution is electrical low-pressure impactor (ELPI). It consists of a low-pressure impactor and a corona charger at the inlet of the ELPI to obtain charged particles composing the aerosol. The low-pressure cascade impactor classifies the particles according to their aerodynamic diameters. Electrometers measure the currents induced by particles sampled on impaction stages that are converted into the particle number concentration (Ouf and Sillon 2009). ELPI allows not only to obtain real-time measurements of aerosol size distribution, but also to collect the particles for their morphological and chemical analyses.

To measure total number particle concentration, different particle counters have been developed, such as optical particle counter (OPC) and condensation particle counter (CPC).

The principle of optical instruments for the measurement of total number particle concentration is the detection of light scattered by individual particles as through a focused beam of light (McMurry 2000). Particle number is determined by counting the pulses of scattered light reaching the detector. Because the intensity of scattered light is related to the size of the scattered particle, this relationship can be used to determine particle size. In order to measure particles below $100 \mathrm{~nm}$, optical particle counters with high light intensity and increased detector sensitivity have been developed. However, they are not able to measure particles much below $50 \mathrm{~nm}$ (Glantschnig and Chen 1981).

In order to measure number particle concentration of smaller NPs, the CPCs, able to count smaller particles down to $2 \mathrm{~nm}$, have been developed. In these counters, the particles are grown by condensation to a size of 10 $12 \mu \mathrm{m}$ to allow their detection. The enlargement of size of particles in the aerosol by condensation requires the creation of a region of supersaturation in a condenser where nucleation occurs (Hering and Stolzenburg 2005). When the aerosol becomes supersaturated, particles above a certain size grow into drops. Then the drops are focused through a nozzle and are counted by a laser 
beam. Either the properties of the vapour and particles or the supersaturation achieved determines the minimum particle size detected by a CPC (Hämeri et al. 2002). Because supersaturation is not the same for all particles, the efficiency of the counter gradually decreases at smaller sizes (Kulkarni et al. 2012).

\section{Inhalation toxicity of gold nanoparticles}

Due to the vast epithelial surface area of the lungs, inhalation is considered the primary route of exposure to NPs, especially at the workplace (Yokel and Macphail 2011). The respiratory tract can be divided into three regions: the nasal cavity, the airways (trachea, bronchi and bronchioles) and the alveolar region where the actual gas exchange occurs (Fytianos et al. 2016). Organs and structures of the respiratory system are shown in Fig. 4.

The tracheobronchiolar region consists of secretory and ciliated epithelial cells. The former produce the mucus, the latter clear the particles and pathogens that have been trapped in the mucus and lead to particle excretion through the mucociliary escalator. This primary defence system is particularly efficient for microndimensioned $(>6 \mu \mathrm{m})$ particles, while smaller particles have more chance to escape clearance (El-Sherbiny et al. 2015).

So, inhaled NPs mainly deposit in the alveolar region and reach the air-blood barrier. The surface of the alveoli is composed of thin type I alveolar epithelial cells, specialised for gas exchange with the underlying endothelium at the air-blood barrier, and the surfactant secreting epithelial type II alveolar cells that are able to proliferate and differentiate into type I cells (Fröhlich and Salar-Behzadi 2014). Type II cells are more abundant, but type I cells constitute more than $95 \%$ of the alveolar surface. Pulmonary surfactant is a lipid-rich film spreading at the alveolar air-liquid interface. It is composed of approximately $80 \%$ phospholipids, $10 \%$ neutral lipids and $10 \%$ proteins. These proteins are the first to come in contact with particles in the respiratory tract and so they are probably among the most abundant constituents of the inhaled particle protein corona, the protein layer that NPs rapidly acquire upon contact with biological fluids (Lundqvist et al. 2008; Marchetti et al. 2015). Surfactant proteins (SP)-B and SP-C contribute to lower the surface tension together with the phospholipids, while SP-A and SP-D are involved in lung defence as components of the innate immune system (Jud et al. 2013). Also, alveolar macrophages and dendritic cells (DC) belong to the host defence system towards potentially harmful inhaled particles and microbes. The first can be found on the internal surfaces of the alveoli (the alveolar ducts) and of the bronchioles; the second have been described both in the conducting airways and in the distal lung, acting as antigen-presenting cells (Holt et al. 1990).

Inhaled particles deposit in the different regions according to their size. In particular, NPs with a size range of 5-100 nm are deposited mainly in the airways and in the alveolar region (Oberdörster et al. 2005). From the alveoli, NPs can diffuse to other organs translocating through the extremely thin air-blood barrier. Therefore,
Fig. 4 Schematic representation of the respiratory system

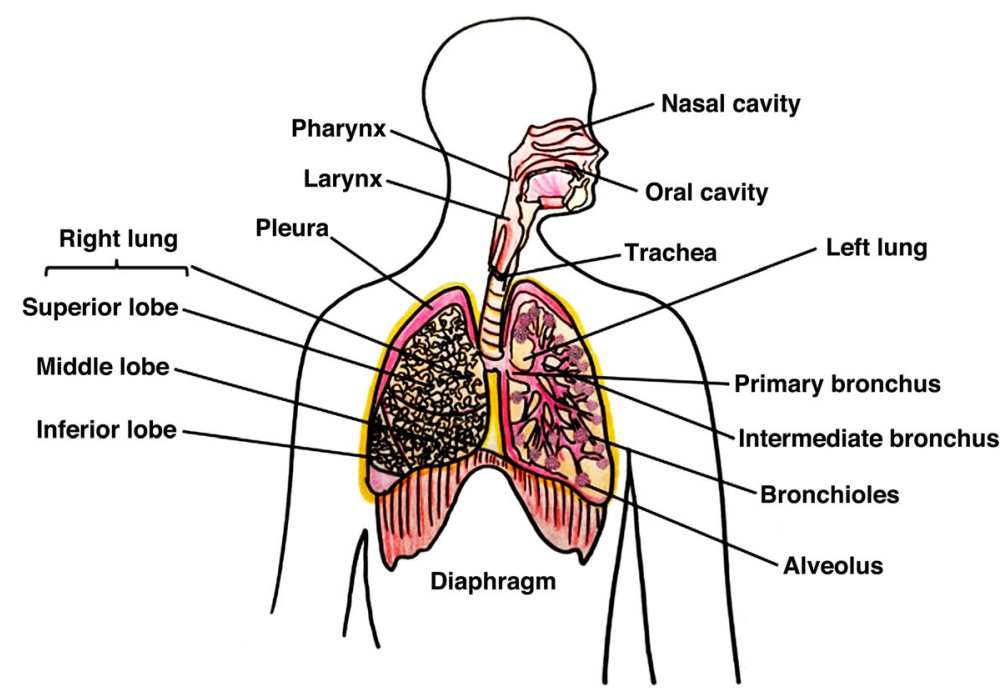


it is extremely important to determine the adverse health effects associated with inhalation of NPs. To this purpose, both cellular and animal models have been used. In vitro models of respiratory exposure offer a simplified approach in which it is possible to concentrate on a few parameters at a time and enable researchers to understand the interaction of ENMs with cells at the molecular level. On the other hand, in vivo studies are essential to investigate the possible toxic effects of ENMs because they mimic, in a more realistic way, the environmental, occupational or intended exposure (Jud et al. 2013).

In this section, we will discuss recent results that address the toxicity of gold nanoparticles, obtained using in vitro or in vivo respiratory systems.

In vitro studies

For in vitro studies on respiratory exposure, bronchial and alveolar cell lines (such as BEAS-B2, HBEC3-KT, A549, MLE-12) are often preferred to primary cells (NHBE), due to their easy and reproducible use as well as their purity. MLE-12 mouse cells and, mainly, A549 human cells, are widely used as in vitro lung epithelial cell models to assess drugs and airborne nanoparticle toxicity in the lung: these cells have many features of alveolar epithelial type II (ATII) cells (Foster et al. 1998) such as the ability to produce surfactant in certain conditions (Wikenheiser et al. 1993; Lieber et al. 1976). Surfactant protein-AuNP interaction largely affects the biological properties of NPs (Saptarshi et al. 2013) and, therefore, should be considered in all in vitro studies on NP-lung interaction (Marchetti et al. 2015; Schleh et al. 2013b). BEAS-B2, HBEC3-KT and NHBE are human bronchial epithelial cells. BEAS-2B, an SV40 large Tantigen-immortalised human bronchial epithelial cell line, has been extensively used in many experimental contexts, such as the screening of chemical and biological agents and respiratory injury tests. Advanced in vitro systems that mimic the airway epithelial barrier have also been successfully utilised to study AuNP toxicity and will be described. Different endpoints have been studied, such as cellular uptake, cytotoxicity, reactive oxygen species (ROS) production and genotoxicity.

As far as uptake is concerned, it is particularly important to study the mechanisms used by different cells to internalise NPs as it can influence their intracellular and extracellular fate. As the results obtained on a limited number of cell types cannot be generalised to all cellular systems, it is indispensable to take into consideration the specific cell type influence on the fate of NPs when NPs are to be used in vivo. Furthermore, genotoxicity is an important parameter to consider since small AuNPs, once internalised, are able to enter the nucleus (Huo et al. 2014) and, interacting with DNA, are likely to cause genotoxicity. Finally, it is well known that metal NPs can induce oxidative stress (OS) (Limbach et al. 2007). OS is the result of an imbalance of the cellular redox potential, where reactive oxygen species (ROS) are produced at an amount that the cellular antioxidant systems are not capable to detoxify (Limbach et al. 2007). As the ROS formation plays a key role in the progression of inflammatory disorders (Mittal et al. 2014), it is very important to measure also this parameter.

\section{Gold nanoparticle toxicity in bronchial cell models}

Vetten et al. (2013) and Vetten and Gulumian (2019) performed two different in vitro studies on the toxicity of AuNPs on bronchial epithelial cells by using labelfree techniques such as cell impedance to analyse both cell adhesion and viability, and dark field and hyperspectral imaging to investigate uptake. The authors characterised AuNP suspensions both in Milli-Q $\mathrm{H}_{2} \mathrm{O}$ and in culture medium. In order to improve the stability of suspensions, they centrifuged the nanoparticles suspended in Milli-Q $\mathrm{H}_{2} \mathrm{O}$ and re-suspended them in culture medium. However, the authors performed the characterisation by TEM and DLS, determining primary size and hydrodynamic diameter of NPs. In the first research (Vetten et al. 2013), the cytotoxicity of AuNPs stabilised with citrate (14 and $20 \mathrm{~nm}$ in diameter, 1$5 \mathrm{nM}$ ) has been studied in BEAS-2B and in cells of different origin (the Chinese hamster ovary cell line $\mathrm{CHO}$, and the human embryonic kidney cell line HEK 293) using both conventional and label-free methodologies. In cytotoxicity studies using conventional assays, cells were treated with $14 \mathrm{~nm}$ AuNPs ( 1 or $5 \mathrm{nM}$ ), whereas, for the assessment of cytotoxicity using cell impedance, the cells were treated with $14 \mathrm{~nm}$ or $20 \mathrm{~nm}$ AuNPs ( $1 \mathrm{nM}, 2 \mathrm{nM}$ and $5 \mathrm{nM})$. Results obtained showed that AuNPs were internalised in a timedependent manner and that toxicity was not related to the uptake level, but depended on the cellular systems and on their specific culture media leading to different NP agglomeration and protein corona formation which, in turn, may influence the uptake and the toxicity of the 
nanoparticles. In fact, AuNPs were internalised in BEAS-2B cells at high levels with minimal toxicity and $\mathrm{CHO}$ cells have proven to be sensitive mainly to $20 \mathrm{~nm}$ AuNPs.

In the second research (Vetten and Gulumian 2019), the authors investigated the influence of NP surface groups on AuNP-cell interactions. Concerning surface chemistry, literature data show that the functionalisation of AuNPs plays a role on cellular uptake and cytotoxicity. The presence of PEG-ligands causes reduction or absence of uptake, compared to colloidal NPs stabilised with citrate (Arnida et al. 2010; Nativo et al. 2008; Rayavarapu et al. 2010; Cruje and Chithrani 2015); however, the additional modification of PEG-ligands can lead to an increase in AuNP uptake. Based on this hypothesis, Vetten and Gulumian (2019) studied the effect of conjugation of different functional groups via PEG on AuNP uptake in BEAS-2B cell line. In particular, hydroxyl-PEG (POH), carboxyl-PEG (PCOOH), biotin-PEG (PBtn), nitrilotriacetic acid-PEG (PNTA) and azide-PEG (PAZ) were utilised. Results obtained showed that none of the different AuNPs was cytotoxic, and among the different PEG NPs, only PCOOH AuNPs were internalised. The uptake mechanism of both citrate-stabilised and $\mathrm{PCOOH}$ AuNPs was caveolin-mediated endocytosis. Following uptake, these NPs could bypass endolysosomal degradation, so the absence of intracellular release of ions can explain the absence of toxicity. These results demonstrate that the mechanism of entry is able to determine the intracellular localisation and the subsequent cytotoxicity. Moreover, these studies highlight that label-free techniques can be appropriate and valuable methodologies for the study of AuNP cytotoxicity and uptake.

Other studies have been carried out to analyse the influence of AuNP surface charge on cytotoxicity by measuring cell viability, cell membrane permeability and cell proliferation. In the study of Giri et al. (2015) on BEAS-2B cells, pentanethiol-coated AuNPs (core diameters of $\sim 2 \mathrm{~nm}$ ) were functionalised with thioalkyl tetra(ethyleneglycol)ated trimethylammonium (TTMA) and tetraethylene glycol (TEGOH) to obtain different percentages of positive charge (from 100 to 96, 65, 20 and $0 \%$ ) by varying the TTMA:TEGOH ratio. The authors characterised AuNP suspensions both in Milli$\mathrm{Q} \mathrm{H}_{2} \mathrm{O}$ and in culture medium. In order to improve the stability of the suspensions, they centrifuged the nanoparticles suspended in Milli-Q $\mathrm{H}_{2} \mathrm{O}$ and re-suspended them in culture medium. However, the authors performed the characterisation only by TEM and determined only the primary size of NPs without giving information on agglomeration of AuNPs and size distribution of AuNP suspensions. Fully positively charged AuNPs (100\% TTMA) were toxic to epithelial cells, while the reduction in the extension of the positive charge resulted in the absence of cytotoxicity. In particular, at $1 \mu \mathrm{M}, 100 \%$ TEGOH particles (fully negatively charged) showed no cytotoxic effect, while 20\% TTMA AuNPs only slightly affected the morphology of cells. Results of experiments in which the effect of $1 \mu \mathrm{M}$ AuNPs on cell proliferation was studied showed that, after 24 and $48 \mathrm{~h}$ of incubation, all positively charged AuNPs significantly decreased cell proliferation. Taken together, the results of this study demonstrated that AuNP surface charge is an essential characteristic that influences their interaction with the cells. Hence, the modulation of the surface charge to a lower positivity can reduce their cytotoxicity and can be utilised to design NPs with improved safety features.

The influence of surface charge on toxicity has been studied more thoroughly using larger AuNPs and three different lung cell systems (Schlinkert et al. 2015). In this study, AuNPs (7 to $10 \mathrm{~nm}$ in diameter) were synthesised with different coating to give different classes of surface charge ranging from -50 to $+70 \mathrm{mV}$ : negatively charged AuNPs, coated with sodium citrate, and positively charged NPs, coated with chitosan (Schlinkert et al. 2015). The characterisation was performed only after the AuNP synthesis. Data on primary size by TEM and surface charge by zeta potential are shown. As the diameters of these AuNPs were in a range of dimensions in which they can be deposited both in the tracheobronchial tract and in the alveoli (Löndahl et al. 2014), the authors selected three different types of human epithelial cells representative of these regions of the respiratory system: the alveolar adenocarcinoma cell line (A549) (Giard et al. 1973), the bronchial epithelial cell line (BEAS-2B) (Albright et al. 1990) and the primary human bronchial epithelial cells (NHBE) (Lechner and LaVeck 1985). As it will be better described in the next paragraph, A549 is the cell line most frequently used as a model for the evaluation of NPinduced pulmonary cytotoxicity, whereas, concerning bronchial cells, BEAS-2B cells have the advantage of rapidly forming a tight epithelium and NHBE cells are primary cells derived from healthy lung tissue. Moreover, all these cell types have already been used as models for in vitro nano-safety inhalation studies 
(Schlinkert et al. 2015). Two different assays were performed to determine the viability of the cells: the measure of membrane integrity and of cell metabolism (proliferation). ROS production was also measured. The results obtained showed that A549 cells were the least sensitive to AuNPs. The highest sensitivity was observed in NHBE cells, in which exposure to AuNPs with a charge greater than $+40 \mathrm{mV}$ induced cellular damage. Only AuNPs with the highest positive charge $(+65-75 \mathrm{mV})$ were toxic for BEAS-2B cells. Positively charged AuNPs induced ROS in all cell types, as already observed in the same cellular systems exposed to titanium dioxide NPs (Ekstrand-Hammarstrom et al. 2011). ROS production was more evident in A549 cells where AuNPs with the highest positive charge $(+65-75 \mathrm{mV})$ also induced the highest amount of ROS. Taken together, the results of this study show that AuNPs, generally considered inert, can become toxic if coated with charged molecules. As a matter of fact, the AuNPs functionalised with chitosan have been demonstrated to be toxic for bronchial cell systems. These results are in agreement with those by Giri et al. (2015), which demonstrated that AuNPs with a positively charged surface were toxic to epithelial cells.

Finally, the effects of AuNPs in bronchial cells were analysed in terms of cytotoxicity, assessed by the Alamar Blue assay, and also in terms of genotoxicity, assessed by the comet assay and the micronucleus test.

In particular, the size-dependent genotoxicity of AuNPs (5 and $50 \mathrm{~nm}$ ) was studied in HBEC3-KT cells, normal human bronchial epithelial cells immortalised with CDK4 and hTERT (Lebedová et al. 2018). AuNPs were characterised by TEM and zeta potential in order to determine the size and the surface charge. PTA analysis has been performed in culture medium to study NP agglomeration. After cell exposure, only the smallest $(5 \mathrm{~nm})$ AuNPs slightly reduced cell viability (tested up to $50 \mu \mathrm{g} / \mathrm{ml})$. Concerning genotoxicity, following $48 \mathrm{~h}$ exposure to AuNPs, only the smallest particles $(5 \mathrm{~nm})$ were active showing 3.3, 5.6 and $7.2 \%$ DNA in tail, in the different concentrations tested $(1,10$ and $20 \mu \mathrm{g} / \mathrm{ml}$, respectively), whereas, at the same concentrations, micronuclei formation was not observed. These results, showing a dimension-dependent DNA damage together with the absence of micronuclei induction, are in agreement with a previous study on AuNP genotoxicity carried out on cells of different origins (Xia et al. 2017; George et al. 2017). The mechanism responsible for the size-dependent genotoxicity of the AuNPs has not yet been fully defined (Lebedová et al. 2018). However, it has been reported that AuNPs smaller than $10 \mathrm{~nm}$, being able to enter the nucleus through the nuclear pores (Huo et al. 2014), can interact with DNA causing genotoxicity.

Results of these studies are summarised in Table 2.

\section{Gold nanoparticle toxicity in alveolar cell models}

The first study on alveolar cells showed that nonfunctionalised $33 \mathrm{~nm}$ AuNPs were internalised and induced apoptosis in A549 cells but not in other cell lines of non-respiratory origin, showing specificity for lung cells (Patra et al. 2007). The authors detected AuNP clusters near the nucleus by fluorescence and confocal microscopy, probably exploiting surface-enhanced Raman effect. Since no TEM observation of cells treated with AuNPs was performed, it was not possible to assess if the NPs were localised in vesicles or free in the cytoplasm. Similar results were obtained with citratestabilised 17-nm AuNPs, which reduced viability in two human lung cell lines (A549 and NCI-H1975), inducing both intrinsic and extrinsic apoptotic pathways, but were found in membrane-bound vesicles inside the cells by TEM (Choi et al. 2012). The authors observed an increase in the particle hydrodynamic diameter (from 36 to $45 \mathrm{~nm}$ ) after incubation in RPMI with $10 \%$ foetal bovine serum, presuming that AuNPs adsorbed the serum proteins present in the cell culture medium, a phenomenon known as protein corona formation (Lundqvist et al. 2008), but they did not explain if the observed toxicity might be due to this adsorption. Other authors, analysing Au nanorod internalisation into A549 cells by TEM, observed that NPs were primarily localised in lysosomes and membranous vesicles but were also found scattered in the cytosol as single particles (Tang et al. 2015). Similar results were obtained by us analysing the entry process of spherical AuNPs in A549 cells (unpublished results). In fact, as shown in Fig. 5, also in our experimental conditions, AuNPs are internalised by the cells and do not enter the nucleus but are observed as cluster confined to the cytoplasm, free or inside membranous vesicles. Taken together, these observations seem to indicate that AuNPs internalised into alveolar cells do not reach the nucleus and are confined into the cytoplasm, independently from their shape and size.

Regarding the effect of size, Kirkpatrick's research group reported a comparable cytotoxicity and 


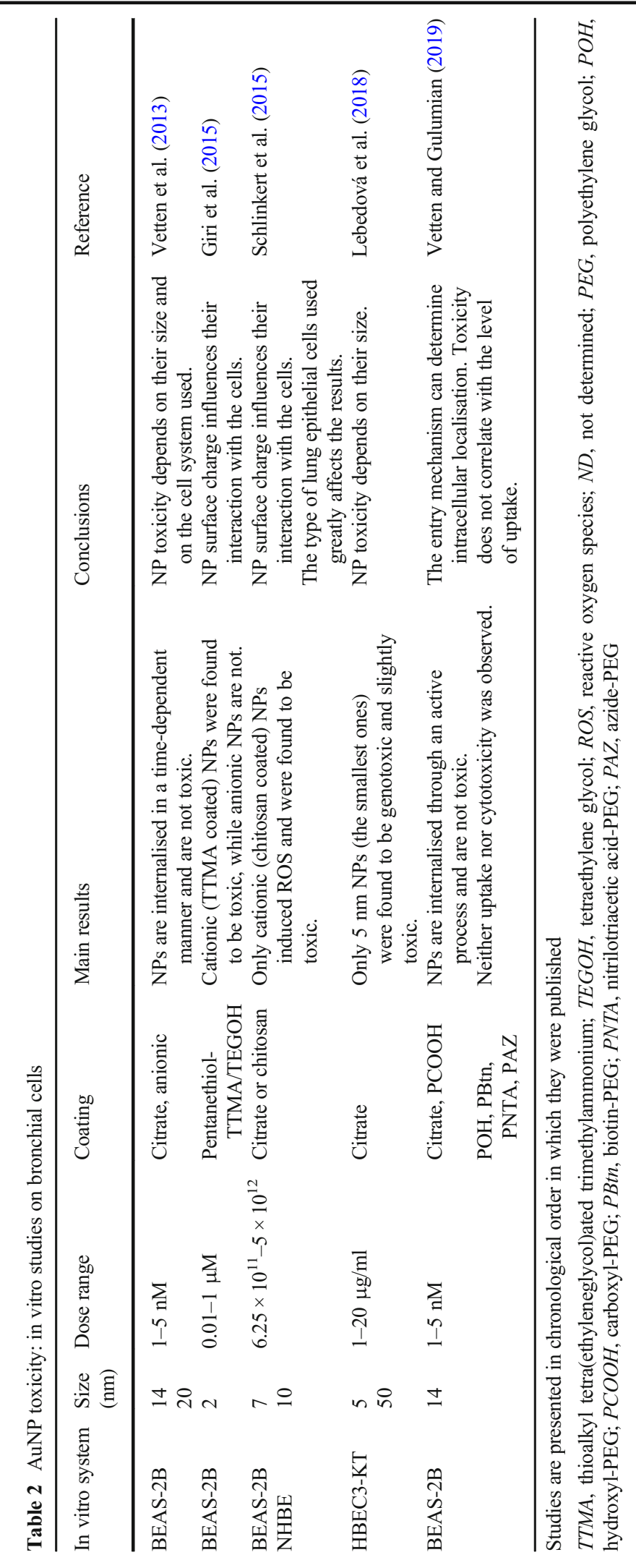



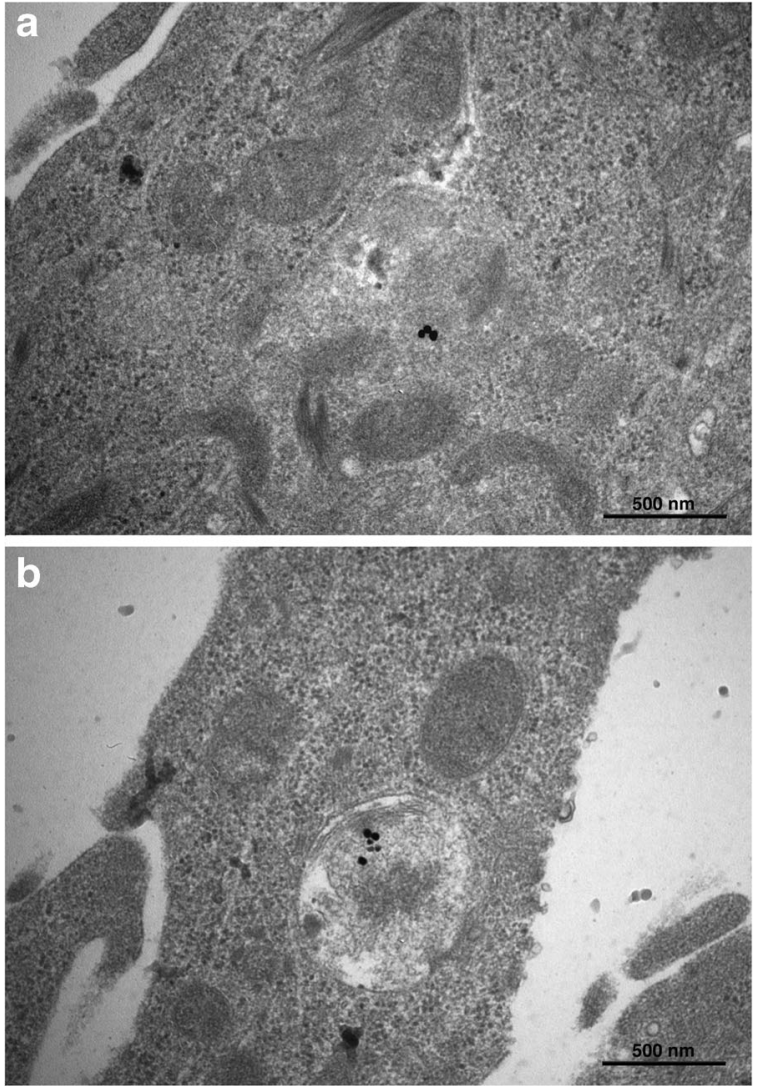

Fig. 5 Ultrastructural analysis of A549 cells exposed for $24 \mathrm{~h}$ to AuNPs (40 nm size) at $20 \mu \mathrm{g} / \mathrm{ml}$. Micrographs show that AuNPs are internalised by the cells and do not enter the nucleus but are confined to the cytoplasm either free (a) or inside membranous vesicles $(\mathbf{b})$

internalisation by active endocytosis of 9,11 and $25 \mathrm{~nm}$ AuNPs in the human alveolar type II cell lines A549 and NCIH441 (Uboldi et al. 2009; Freese et al. 2012). The uptake was independent on the presence of a citrate coating that, instead, could affect both cell viability and proliferation. Conversely, Choudhury et al. (2013) reported that $40 \mathrm{~nm}$ AuNPs were more toxic to A549 cells than 20 and $60 \mathrm{~nm}$. This study is particularly important because it suggests for the first time that the mechanism of AuNP-induced toxicity in A549 cells involves microtubule aggregation followed by cell cycle arrest and apoptosis (Choudhury et al. 2013).

The green synthesis of ENMs, in which plant extracts can play the role of a reducing agent to synthesise metallic NPs, is becoming more and more attractive, the main advantage being the substitution of noxious chemicals with eco-friendly components. However, there are not many studies comparing the toxicity of biologically synthesised AuNPs with those chemically synthesised on respiratory cells. Sathishkumar et al. (2015) obtained 20-50 nm AuNPs by incubating chloroauric acid with star anise extract (SA-AuNPs) and compared their toxicity to chemically synthesised AuNPs in A549 cells. The authors showed that SAAuNPs, probably because of the protective capping by polyphenols present in the extract, were less effective apoptosis inducers and therefore less cytotoxic than chemically synthesised AuNPs. Hence, they suggest that this green method is a good candidate for the synthesis of AuNPs, provided that batch-to-batch variations are kept to a minimum. It is though important to point out that chemically and biologically synthesised AuNPs used in this study had different sizes and so they should not be compared. Moreover, SA-AuNPs were not homogeneous regarding characteristics that can influence their behaviour in a cell system such as size (20$50 \mathrm{~nm}$ ) and shape, as shown by the presence of triangular- and hexagonal-shaped platelets in addition to particles in TEM micrographs of the NP suspension. As a general rule, it is not useful to add too many variables when comparing the effect of ENMs, since this can lead to confusing results.

Concerning the effect of mode of synthesis on metallic NP cytotoxicity in respiratory cells, Park et al. (2017) described the use of mangosteen (Garcinia mangostana) pericarp waste extract to synthesise gold (GM-AuNPs) and silver (GM-AgNPs) nanoparticles and compared the cytotoxicity of the different biologically synthetised metallic NPs. Spherical GM-AuNPs with an average size of $15.37 \pm 3.99$ to $44.20 \pm$ $16.99 \mathrm{~nm}$ were observed in high-resolution TEM (HRTEM) images. The cytotoxicity and apoptosis induction in A549 and mouse fibroblast cells were analysed using a water-soluble tetrazolium assay and the Annexin V/ propidium iodide staining, respectively. The results obtained showed that GM-AgNPs were toxic and induced apoptotic cell death, whereas GM-AuNPs showed no significant cytotoxicity, suggesting that low AuNP toxicity may be related to NP composition.

Colorimetric assays are widely used to test in vitro cytotoxicity of chemicals, but when used to test ENMs, interference phenomena may arise. In this view, Chuang et al. (2013) performed a study to validate a dye-free system to monitor cell growth measuring electric impedance of the monolayer that was already described for bronchial cells (Vetten et al. 2013; Vetten and Gulumian 2019). To test the toxicity of Au nanorods, the system 
was compared to classical methods (trypan blue, 3-(4,5dimethylthiazol-2-yl)-5-(3-carboxymethoxyphenyl)2-(4-sulfophenyl)-2H-tetrazolium (MTS), colony formation assay) in different mammalian cell lines, including lung cells like A549 and MRC5 (human normal lung fibroblast) and non-respiratory cells like human gastric adenocarcinoma cells (AGS). Results showed that ROS production and apoptosis makes a major contribution to $\mathrm{Au}$ nanorod-induced inhibition of cell growth in AGS cells. On the contrary, neither ROS production nor apoptosis, but rather a cell cycle delay, was induced by Au nanorods in A549 cells. The gradual and steady slowing of the cell growth rate was measured with all tested methods, suggesting that the cellimpedance measurement system is reliable for the evaluation of NP toxicity. Moreover, impedance results were similar in MRC5 cells, which do not efficiently take up dyes, providing an alternative method when it is not possible to use colorimetric tests. This study confirms in other respiratory cell lines what was suggested by Vetten et al. (2013) for bronchial cells. Other authors had similar results regarding the toxicity of bigger size Au nanorods in A549 cells using traditional assays, but they obtained completely different results on ROS production, demonstrating that the oxidative stress induced by the nanorods may be the main cause of toxicity (Tang et al. 2015). A different conclusion was reached in the study of Aueviriyavit et al. (2014) in which AuNPs had no effect on ROS generation in intestinal cells (Caco-2). Interestingly, the results of Tang et al. (2015) are in agreement with what was reported by Schlinkert et al. (2015). As already described, these authors observed that positively charged AuNPs induced ROS in respiratory cells and, in particular, that ROS production was most prominent in A549 cells. These results are particularly interesting in that ROS formation has been linked to inflammation and apoptosis (Schlinkert et al. 2015).

In the attempt to recreate in vitro the microenvironment of the lung alveoli, Breitner et al. (2015) set up an experimental model consisting of A549 cells and artificial alveolar fluid (AAF) containing salts supplemented with phosphatidylcholine, exposed to a dynamic flow at accurate physiological rates. Data obtained from the analysis of tannic acid-coated $60 \mathrm{~nm}$ AuNP spectral profiles and DLS measures showed that incubation with AAF resulted in loss of stability and enhanced particle agglomeration and sedimentation. Consequently, when AuNPs in AAF were added to the cells in static conditions, NP deposition was more than double compared to
AuNP suspended in medium, due to the presence of large agglomerates. Introducing the variable of dynamic flow did not cause any change because the flow rate, set to low to mimic physiological conditions, was not strong enough to affect NP deposition. By TEM analysis, AAF-suspended AuNPs in static conditions were observed as aggregates both bound to the cell surface and within intracellular vacuoles, while in dynamic conditions, all AuNPs remained associated to the outer surface of the plasma membrane and no internalised particles were identified. This might be due to the morphological changes caused in the cells by the experimental microenvironment, i.e. cell elongation and membrane alterations induced by AAF and dynamic flow, respectively. This means that both fluid environment and flow status can influence NP deposition and internalisation, confirming the importance of incorporating as many physiological variables as possible in in vitro models. These results suggest that in physiological conditions, inhaled NPs are not efficiently internalised into lung cells. However, further studies are required to confirm this hypothesis. For example, the contribution of surfactant proteins, not considered in this study, should be taken into account because they may deeply affect the surface chemistry of the NPs and, consequently, their stability, aggregation status and interactions with cells (Lundqvist et al. 2008; Marchetti et al. 2015).

Exposure to aerosol experiments can be performed in respiratory cells grown in submersed culture or kept in air-liquid interface (ALI) conditions, a more advanced model of respiratory exposure. In the ALI system, cells are cultured on transwell insert, which are placed into a culture well; the medium is supplied from the basal site; and cells are exposed to an aerosol at the apical part. The exposure apparatus consists of a nebuliser, an exposure chamber and a flow system, that mimics the physiological conditions of aerosol inhalation in the lungs more realistically (Lenz et al. 2009). Brandenberger et al. (2010a) using this exposure system on cells grown in ALI conditions reported the quantitative analysis of citrate- and PEG-coated AuNP uptake in A549. Here, the authors describe how surface coating may change the internalisation pattern of the particles. For example, citrate-stabilised AuNP uptake, which was the most efficient, occurred mainly by macropinocytosis, while PEG-coated AuNPs were internalised mostly by caveolin-clathrin-mediated endocytosis. Successively, using the same exposure system, Bachler et al. (2015) studied 
AuNP translocation across the lung epithelial tissue barrier combining in vitro and in silico methods. In this study, the authors confirmed that alveolar epithelial cellular monolayers grown for few days on cell culture inserts and exposed to the particles at the air-liquid interface can represent the air-blood barrier to model AuNP translocation. Moreover, they used a physiologically based pharmacokinetic model to predict the distribution of AuNPs to secondary organs. Results from this research showed similar translocation kinetics of AuNPs through the human A549 and murine MLE-12 alveolar type II cell lines, suggesting the absence of specie-specific mechanisms. The translocated fraction was independent of the applied dose (up to $100 \mathrm{ng}$ / $\mathrm{cm}^{2}$ ) and, as expected, was inversely proportional to the particle size. These results are encouraging since they show the feasibility of improving in vitro models with the contribution of in silico models to more realistically mimic in vivo exposure.

To improve the predictive value of in vitro experiment of exposure to NPs, advanced culture models have been developed by several authors of the same research group (Rothen-Rutishauser et al. 2007; Brandenberger et al. 2010b; Fytianos et al. 2017; Durantie et al. 2017). They set up a triple cell co-culture model of the human airway wall (also called 3D lung model) composed of epithelial cells (A549), monocyte-derived macrophages (MDM) and monocyte-derived dendritic cells (MDDC) from human blood monocytes. A549 cells were grown for a few days on cell culture inserts (polyester membrane, $3.0 \mu \mathrm{m}$ pores) before MDM addition on top of the epithelial monolayer and MDDC underneath the insert. Both the material and the size of the pores are very important since it is known that pores as small as $0.4 \mu \mathrm{m}$ and polycarbonate membranes are likely to hinder the free passage of NPs (Fröhlich 2018). In an early study, they found that in this cell model, exposed to bovine serum albumin-coated $25 \mathrm{~nm}$ AuNPs as suspension in submerged conditions, there was a significant increase of the pro-inflammatory cytokine tumour necrosis factor- $\alpha$ (TNF- $\alpha)$. Moreover, by energy filtering TEM, they showed that AuNPs could be seen in all cell types as free particles and also in the nucleus (RothenRutishauser et al. 2007). To obtain an even more accurate alveolar model, Brandenberger et al. (2010b) used the same triple cell co-culture in ALI conditions. When the triple cell culture was ready, the medium was removed from the upper transwell chamber and the cells were kept in air-liquid interface conditions for $24 \mathrm{~h}$ prior to particle exposure. The cultures were then transferred to the exposure chamber where they were incubated with aerosolised $15 \mathrm{~nm}$ AuNPs for $20 \mathrm{~min}$ and kept in air-liquid interface conditions for different postexposure times. In these conditions, which mimic particle deposition in vivo, not only particle agglomeration was decreased, but it was possible to obtain a more homogeneous and efficient particle deposition. In this system, no inflammatory response was induced by AuNP treatment, and although the particles were able to enter the cells and translocate, they were seen in intracellular vesicles (Brandenberger et al. 2010b) and not free in the cytoplasm as in the previous report (Rothen-Rutishauser et al. 2007). As expected, different ways of exposure elicit different cell response and results obtained in air-liquid interface conditions (Brandenberger et al. 2010b) contradict with what was reported in submerged conditions (Rothen-Rutishauser et al. 2007). On the other hand, these results on uptake are in agreement with those obtained with classical experiments showing that AuNPs enter the cells by endocytosis and therefore can be found inside the cells surrounded by lipidic membranes (Choi et al. 2012; Uboldi et al. 2009; Freese et al. 2012; Tang et al. 2015).

Fytianos et al. (2017) used the aerosol exposure system to expose a 3D lung model grown in ALI conditions to poly(vinyl alcohol) (PVA)-coated AuNPs functionalised with an antibody specific for dendritic cells (DC-SIGN), plus a negative (PVA-COOH) or a positive (PVA-NH2) surface charge. They evaluated the possibility of using nanocarriers to target immune cells with the aim of enhancing or suppressing the immune response in the lung. As expected, they found a significant increase of particle uptake by dendritic cells. As regards the non-DC-targeted AuNPs, the positive charged ones were taken up more easily, especially by macrophages, while uptake was low for all NPs in A549 cells. None of the particles induced any cytotoxic effect that could be ascribed to the gold itself, nor increased cytokine secretion. These results are in agreement with the observation that the positive surface charge can enhance AuNP uptake efficiency (Hauck et al. 2008; Alkilany et al. 2009; Cho et al. 2009; Liang et al. 2010; Liu et al. 2013).

In a biodistribution study, Durantie et al. (2017) investigated the effect of NP aggregation on cellular uptake and translocation in the same multicellular lung system described above. Citrate-capped $14.5 \mathrm{~nm}$ core size AuNPs were prepared and coated with tiopronin to 
add carboxylic groups on the surface. AuNP aggregation was obtained by protonation of the negatively charged groups. Both single and aggregated tiopronincoated AuNP solutions were stabilised with a polymer mixture of PVA/PAAm (poly(allylamine)) generating particles with final hydrodynamic diameters of $32 \mathrm{~nm}$ and $106 \mathrm{~nm}$, respectively. These sizes are consistent with TEM images showing that each aggregate was composed by a mean of 4 single AuNPs. Cells were exposed to aerosolised AuNPs onto the air-liquid interface for 4,24 and $48 \mathrm{~h}$ and no cytotoxic or proinflammatory effect was observed. Both single and aggregated AuNPs were internalised, and although the uptake of aggregated AuNPs was faster, the final result was similar. Also, the translocation rate across the lung barrier model was not affected by the aggregation status of AuNPs and was quite low (2-5\%), similar to what was found in vivo (Lipka et al. 2010; Schleh et al. 2013a; Kreyling et al. 2014). Taken together, these results suggest that the aggregation status of AuNP suspensions can affect cellular uptake kinetics early during exposure. Moreover, this study proposes a sophisticated in vitro model, able to mimic NP behaviour and cell response in a realistic way, as a useful tool for this kind of studies.

Results of the studies on the different alveolar cell models are summarised in Tables 3 and 4 .

Results of studies in the different alveolar cell systems showed that AuNP surface charge influences their interaction with cells; hence, these NPs, generally assumed inert, can become toxic if coated with positively charged molecules. Moreover, advanced in vitro lung models and exposure systems suggest that the closer we get to physiological conditions, the lower is the NP toxicity. Concerning the air-liquid interface system to expose lung cells, it must be taken into consideration that it requires cell culture inserts so, in these studies, AuNP toxicity has been generally assessed analysing cell morphology, cell layer integrity, release of the cytosolic enzyme lactate dehydrogenase and proinflammation response. Therefore, the difference in AuNP toxicity could be due to the different parameters examined.

Overall, the in vitro works highlight a lack of information on the preparation of AuNP suspensions in the culture medium used in the assays and on dispersion procedures. Not all authors perform the characterisation of the AuNPs suspended in the culture medium, crucial to understand the changes in their physico-chemical characteristics, such as agglomeration, surface charge and the adsorption of serum protein that influence the interactions with cell systems.

Taken together, results from in vitro studies show that surface charge influences AuNP interaction with cells and, consequently, their cytotoxicity. NP uptake mechanism can be affected by surface charge, but unfortunately, this aspect has not been considered by most authors. However, these investigations have an important flaw, as charge and size are not studied simultaneously. As a matter of fact, only Lebedová et al. (2018) utilised two NPs of very different size without considering the influence of charge, whereas the other studies, that considered the influence of charge, have the limitation of using NPs in a very narrow size range.

In vivo studies

As reported above, NPs can be inhaled or ingested while using products containing ENMs, and it is well known that inhalation represents the most common route of exposure to NPs in the workplaces (Yah et al. 2012).

NPs can be inhaled in the form of aerosol or powder suspensions, or artificially administered by instillation into the respiratory tract for toxicity studies. Once NPs have reached the lungs, they can remain there or enter the bloodstream and move to other organs or cells, with the probability of bioaccumulation in the heart, the spleen, the kidneys, the bone marrow and the liver.

As shown in the previous paragraphs, although several cytotoxicological studies have been conducted on AuNPs, there is no systematic procedure that has given definitive results. This is because the different studies have used not only different biosystems, but also, regardless of the size and shape of the particles, various types of coating. These variants, such as size, surface charge, etc., are extremely important, since the molecules or ions that surround the AuNPs produce first contact with the biosystem of interest. Consequently, no definitive conclusions could be drawn from these investigations.

In vitro studies focussing on the toxicological effects of AuNPs greatly outnumber in vivo studies; the latter are obviously more demanding, but take into account the complexity of the organism, hence more in vivo toxicology studies are needed to assess AuNP safety, including long-term studies for workers' exposure. Although inhalation represents the main route of exposure 


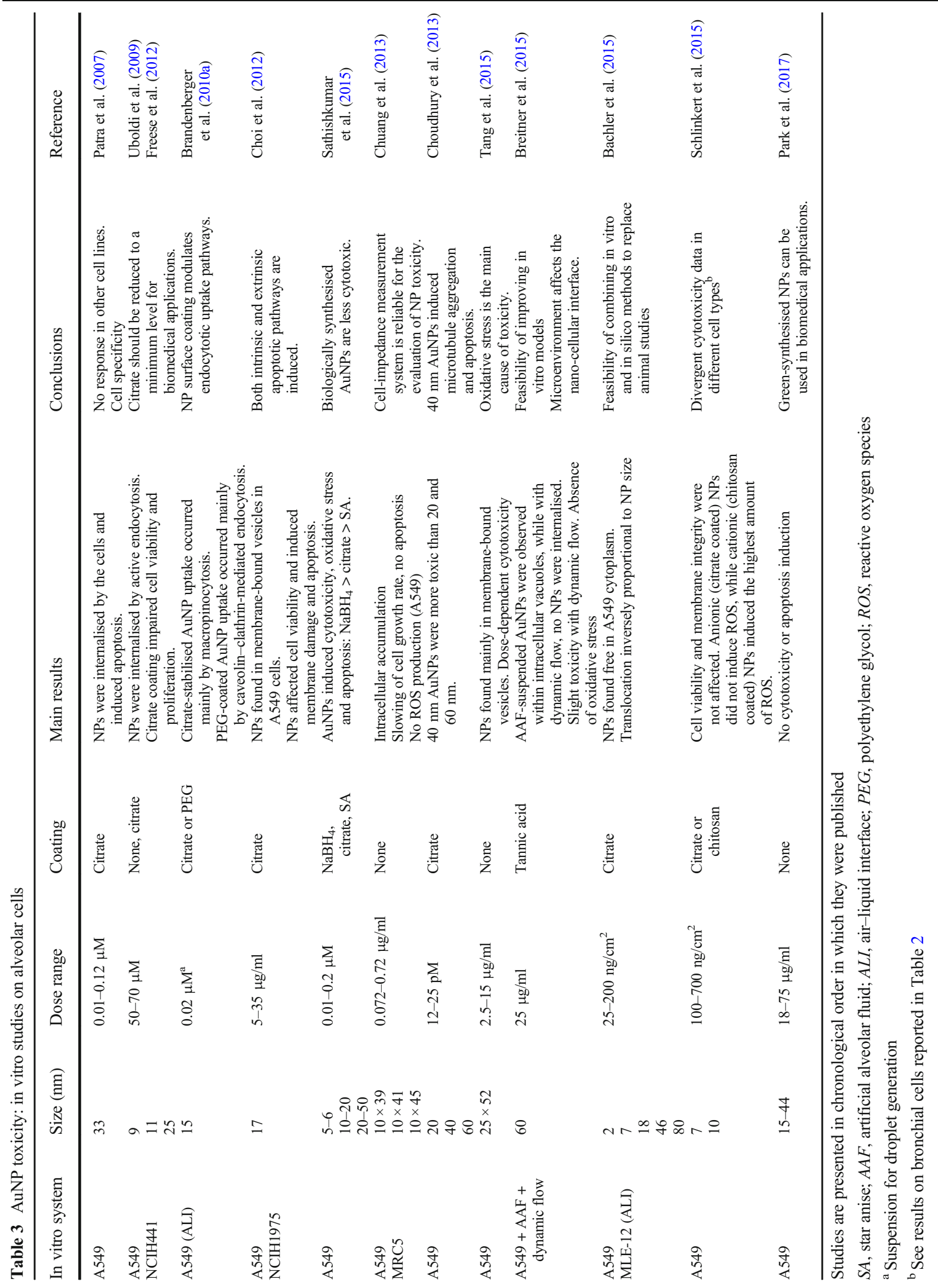




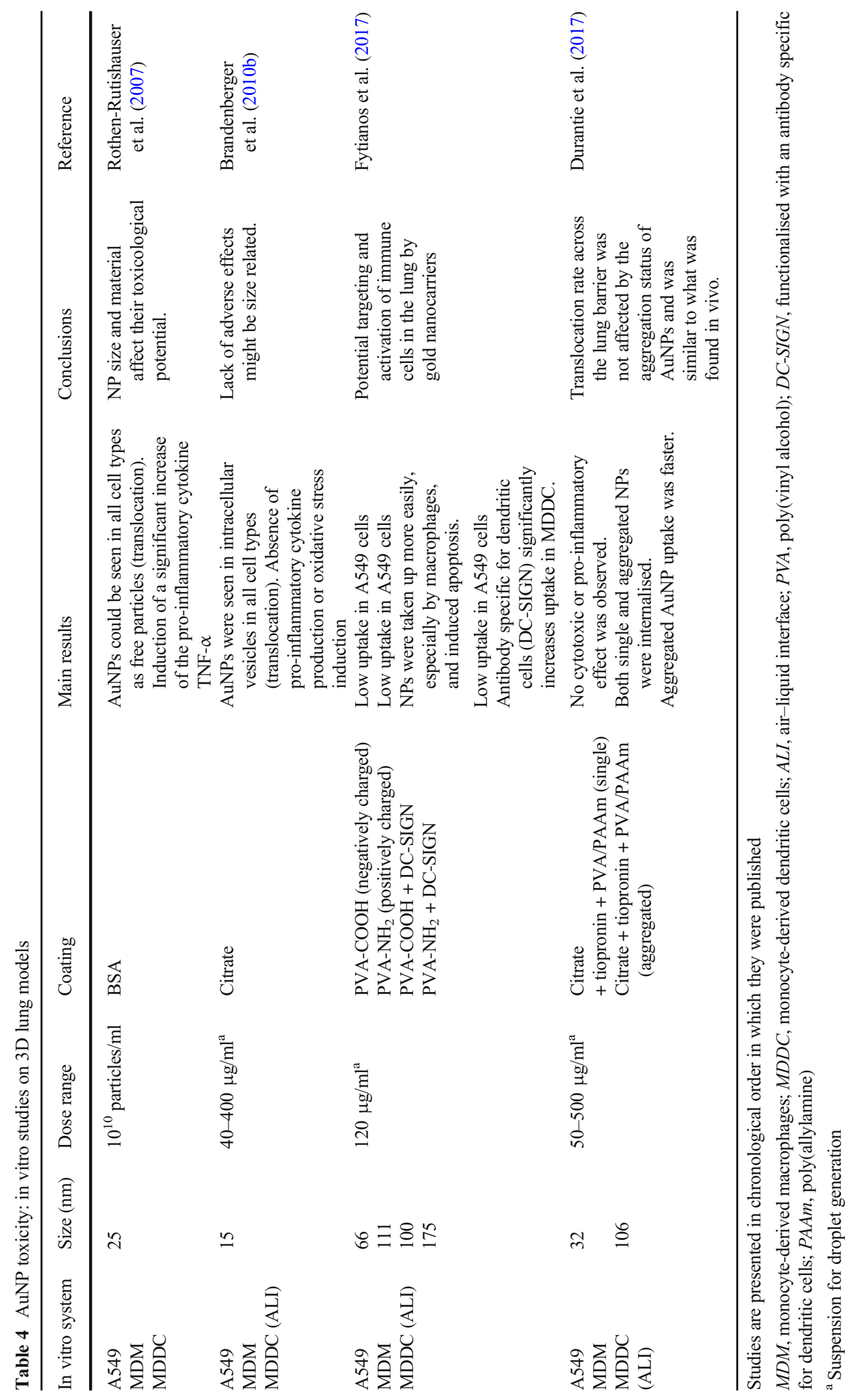


for workers, researchers and consumers, intravenous injection of AuNPs is often used for in vivo studies. As it is easily understandable, this method of NP administration does not reflect reality, and results from these studies are not predictive of the risk associated to AuNP use and manipulation. To overcome these limitations, inhalation toxicity studies using different in vivo models have been performed, as a step towards understanding the adverse effects of inhaled NPs on human health. The main routes of administration used in these studies were inhalation (mainly intratracheal) and intratracheal instillation. The path of absorption of NPs through the lungs is of critical importance and the gold standard analysis for evaluating the pulmonary toxicity effects of respirable NPs is represented by inhalation studies, as the physiological exposure route is similar to that in humans. It must be considered that these studies have a high cost and require not only complex structures to accommodate large apparatus but also the mastery of the handler's skills. Differently, in intratracheal instillation studies, NPs are administered directly through the trachea, so this approach is suitable for studying the dose-response relationship; in addition, this method is inexpensive and complex structures are not required. However, in this type of administration, the agglomeration of NP suspensions, transferred in a single bolus to animals, occurs. Here, we examined the similarities and discrepancies between NP-induced lung toxicity data obtained from inhalation and intratracheal instillation studies. Since there are no references in which inhalation and intratracheal instillation studies have been conducted using the same nanoparticles, we reviewed in vivo studies that used only one of the two experimental systems and compared the data on the pulmonary toxicity. The results of these studies are analysed and discussed below.

\section{Intratracheal instillation studies for the evaluation of AuNP-induced lung toxicity}

On the basis of the results obtained in various in vitro models of the respiratory tract, demonstrating that AuNP toxicity is inversely proportional to the size, Semmler-Behnke et al. (2008) selected two different sizes of NPs, i.e. the extremely cytotoxic $1.4 \mathrm{~nm}$ and the non-cytotoxic $18 \mathrm{~nm}$ radioactive AuNPs, both equipped with the same molecules of ligand $\mathrm{Ph}_{2} \mathrm{PC}_{6} \mathrm{H}_{4} \mathrm{SO}_{3} \mathrm{Na}$, for a study on biodistribution after intratracheal instillation of AuNP aqueous solution in female Wistar-Kyoto rats. Unlike the intravenous injection, which represents the established administration route in biodistribution studies, intratracheal administration is more complicated but more suitable to determine the translocation from the respiratory tract to the blood. The authors claimed that the method of choice, reproducible inhalation of NPs, has not been applied for these experiments because of the difficulties arising from the need for radiation protection. When using intratracheal administration, up to $25 \%$ of the NPs are eliminated from the lungs by mucociliary clearance, swallowed into the gastro-intestinal tract and excreted via faeces. As expected, a different biodistribution was observed for the different NPs. After $24 \mathrm{~h}$, the 18-nm NPs were retained nearly completely $(99.8 \%)$ in the lung, whereas the 1.4-nm NPs were found in significant amounts in the blood, liver, skin and carcass. So, the smallest NPs can overcome the air-blood barrier of the lungs, with subsequent distribution throughout the body. As for the difference in the route of administration (intratracheal instillation or intravenous injection), it is interesting to note that when the authors used the two systems they observed that the relationships between the organs were quite different. As for the 1.4-nm AuNPs: for instance, the liver/spleen ratio was 17.5 after instillation and 36.5 after intravenous injection, and the liver/blood ratio was 1.1 after instillation and 12.5 after intravenous injection. These findings are particularly significant in the discussion concerning risk assessment of AuNPs.

In a subsequent study, adult female mice were intratracheally instilled with 5 doses $(50 \mu \mathrm{l} /$ dose $)$ of AuNPs (2, 40 and $100 \mathrm{~nm}$ in diameter) distributed over a period of 21 days (Sadauskas et al. 2009) in order to investigate the role of size in the translocation. The authors did not characterise AuNP suspensions in detail and only claim that NPs, produced by citrate reduction, were spherical, monodisperse and negatively charged. Most of the instilled NPs were found in lysosome/ endosome-like organelles of the lung macrophages, while only a tiny fraction translocated into systemic circulation. The translocation rate was highest for $2 \mathrm{~nm}$ particles and the liver was found to be the major site of deposition. These results are in agreement with the previous study of Semmler-Behnke et al. (2008) in which significant translocation of small AuNPs (1.4 nm) to the liver has been reported. Concerning $40 \mathrm{~nm}$ AuNPs, no gold was found in the liver except for one mouse in which $3 \%$ of the instilled gold was found, whereas no gold was detected in the liver of mice 
instilled with $100 \mathrm{~nm}$ AuNPs (Sadauskas et al. 2009). These results are in agreement with previous observations suggesting that only small amounts of inhaled or instilled AuNPs are translocated from the lungs (Takenaka et al. 2006; Hainfeld et al. 2008).

In order to assess the toxic and inflammatory potential of 5 different types of NPs, including AuNPs, apolipoprotein $\mathrm{E}$ knockout mice, a sensitive model for pulmonary effects and wild-type mice have been used (Jacobsen et al. 2009). The goal of the research was to study the differences of markers of inflammation, lung damage and genotoxicity in lung tissue and bronchoalveolar lavage (BAL) fluid following pulmonary exposure by NP intratracheal instillation in the two mice models. The characterisation of the NP suspensions was performed only by DLS and was not obtained for all samples, probably because of agglomeration and settling problem in the samples. Concerning the 2-nm AuNPs, DLS analysis showed that most particles occurred between 40 and $200 \mathrm{~nm}$ in size. However, the size distribution by volume was broad and ranged from $40 \mathrm{~nm}$ to $1.5 \mu \mathrm{m}$ with the average size of about $140 \mathrm{~nm}$. The results showed that AuNPs, used at a much lower mass dose than the other NPs, were the least inflammatory and DNA-damaging comparing to the others and that the instillation of AuNPs induced a greater pulmonary inflammatory response (corresponding to their surface areas) in apolipoprotein E knockout mice compared with wild-type mice.

The inflammatory potential of AuNPs has been also investigated by Gosens et al. (2010). These authors studied the role of $\mathrm{Au}$ particle agglomeration on the inflammatory response in the lungs of male WU Wistar-derived rats, analysing the effect of the individual AuNPs, suspended in ultrapure water, with respect to the agglomerated NPs, diluted in PBS. Concerning the characterisation, the authors determined the concentration of NP suspension by inductively mass spectrometry, the size distribution by tracking analysis of NP Brownian motion, the primary size, the size and the chemical composition by TEM equipped with EDX spectrometer, as well as the NP charge by zeta potential. This approach allows assessing the effect of the physico-chemical properties of NPs and, in particular, of their agglomeration on the inflammatory response in the lungs. In this study, a single dose of $1.6 \mathrm{mg} / \mathrm{kg}$ body weight in $0.5 \mathrm{ml}$ of $50 \mathrm{~nm}$ or $250 \mathrm{~nm}$ AuNPs was delivered in the rat lungs by intratracheal instillation, and after 3 and $24 \mathrm{~h}$, animals were sacrificed to analyse biological effects. Results obtained showed that after the instillation of agglomerates or single gold particles of different sizes, no significant differences were observed in the lungs and systemic toxicity markers and both agglomerated as well as single NPs generate a mild inflammatory reaction and were absorbed by macrophages. The authors conclude that individual $50 \mathrm{~nm}$ AuNPs do not represent an acute risk greater than their own agglomerates or slightly larger NPs when using pulmonary inflammation as toxicity marker.

Concerning the role of surface properties, such as surface charge, on the biodistribution of AuNPs, Lipka et al. (2010) have studied the biokinetics of PEGmodified or plain AuNPs after intravenous or intratracheal applications in healthy female WistarKyoto rats. For this study, neutron-activated $5 \mathrm{~nm}$ AuNPs were either stabilised with bis(psulfonatophenyl)-phenylphosphine (198Au-Phos NPs) or surface-modified with PEG-750 (198Au-PEG750 NPs) or PEG-10k (198Au-PEG10k NPs) on top of a polymer shell. PEG-coated AuNP suspensions were characterised by DLS in order to determine hydrodynamic diameter, size distribution and surface charge. The authors used UV-vis spectra to determine the size core of NPs. No TEM data on primary size of NPs, core of NPs and thickness of PEG coatings were showed. Concerning intratracheal instillation, NP aqueous suspensions were applied to the animals as previously described (Semmler-Behnke et al. 2008). Only a minor translocation into the circulation and secondary organs (about $0.70 \%$ for 198Au-PEG750 NPs, $0.92 \%$ for 198Au-PEG10k NPs, and $2.60 \%$ for $198 \mathrm{Au}-\mathrm{Phos}$ NPs) was observed within the first hour. After $24 \mathrm{~h}$ the translocation percentages were lower. This study showed that PEGylation did not influence the total translocation from the lungs and that, most importantly, almost all intratracheally instilled NPs (>97\%) were retained in the lungs.

To investigate in-depth the role of physico-chemical characteristics such as size, surface specific area (SSA) and surface charge, on the biokinetics of AuNPs, Kreyling et al. (2014) have instilled intratracheally NPs of various sizes into female Wistar-Kyoto rats: six different NP preparations with negative charge $(1.4,2.8,5,18,80,200 \mathrm{~nm})$ and one NP preparation with positive charge $(2.8 \mathrm{~nm})$. The authors showed a detailed table of physico-chemical characteristics of AuNPs used in the intratracheal administration, specifying that the hydrodynamic diameter and 
polydispersity index of all NP suspensions were assessed just prior to the in vivo experiment. Results obtained showed that $24 \mathrm{~h}$ after administration, most of the NPs were revealed in the lungs, regardless of their charge and that the translocation and retention in secondary organs were two distinct processes, both depending on SSA and surface charge. Concerning $2.8 \mathrm{~nm}$ AuNPs, the translocation of the negatively charged NPs was significantly higher compared to the positive ones. Finally, smaller AuNPs crossed the air-blood barrier more easily confirming that inhaled AuNP translocation depends on nanoparticle size. Instead, the retention of most secondary organs was independent of this NP property, with the exception of kidneys.

Tsuda et al. (2019) conducted a study to evaluate the translocation of NP through the air-blood tissue barrier of the lungs in newborn animals of various ages. In this research, intratracheal instillation was used in order to avoid ingestion of nanoparticles by the gastro-intestinal tract through the deposition of particles in the nasopharynx. These authors characterised spherical AuNPs of $5 \mathrm{~nm}$ and $100 \mathrm{~nm}$ coated with PVP dispersed in water solutions using various techniques (e.g. DC, DLS, TEM, ICPS) to determine morphology, primary size, hydrodynamic diameter, size distribution and surface charge. The authors selected a concentration of AuNP aqueous suspension of $1 \mu \mathrm{g} / \mu \mathrm{l}$ in order to administer a volume instillation ( $1 \mu \mathrm{l} / \mathrm{g}$ body weight) enough to allow a wide distribution when delivered to the lungs, but small enough not to disturb breathing. They selected an AuNP administered dose of $0.027 \mu \mathrm{g} / \mathrm{cm}^{2}$, estimated to be low enough not to cause lung injury and inflammation but high enough for accurate inductively coupled plasma-mass spectrometry (ICP-MS) detection. The results of this study showed that the translocation of NP from the lungs to the rest of the body is significantly higher in infant animals and decreases with increasing age. Based on this observation, infancy can be considered a critically vulnerable window in terms of NP translocation through the lungs. Furthermore, the lack of difference in translocation between 5 and $100 \mathrm{~nm}$ AuNP in infants, contrary to what was observed for adults, who undergo size-dependent translocation, suggests that there could be a significant involvement of paracellular transport in structurally immature lungs compared to adults.

Naota et al. (2013) used morphological approaches to investigate the distribution of $20 \mathrm{~nm}$ AuNPs in the lungs of male 5- or 6-week-old ICR mice. These authors did not assess the physico-chemical characteristics of NPs, showing only the nominal size $(20 \mathrm{~nm})$. At $15 \mathrm{~min}$ after instillation, the mice were killed and the lungs were then immediately fixed for AuNP morphological localisation with the aim of elucidating the relationship between endocytosis and the translocation of nanoparticles at the air-blood barrier. Accumulation of agglomerated AuNPs was detected in the cytoplasm of macrophages, on the surface of alveolar epithelial cells and in the alveoli. Results of this study demonstrated that instilled colloid NPs were internalised into the alveolar epithelium at the air-blood barrier by caveolae-mediated endocytosis.

Taken together, these intratracheal instillation studies have produced interesting observations useful for the estimation of the hazard associated with respiratory exposure to AuNPs. Despite the difficulty of comparing such different experimental conditions, as the authors have not always characterised AuNP suspensions in detail, in general, we can say that: (i) most of the instilled NPs have been found in lysosome/endosomelike organelles of the pulmonary macrophages while only a small fraction is able to translocate into systemic circulation and NPs are internalised into the alveolar epithelium at the air-blood barrier by caveolaemediated endocytosis; (ii) the translocation rate is highest in infant animals and, in general, for positive and smallest nanoparticles that can overcome the airblood barrier of the lungs, with subsequent distribution throughout the body, the liver appearing to be the main deposition site; (iii) when knockout animal models have been used as sensitive model for pulmonary effects, instillation of AuNPs has induced a greater pulmonary inflammatory response in this animals compared to the wild-type mice; (iv) studies in which AuNP suspensions have been characterised in detail showed that individual AuNPs do not represent an acute risk greater than their own agglomerates when using pulmonary inflammation as toxicity marker (however, large AuNPs of $50 \mathrm{~nm}$ have been used in these studies); (v) studies with a careful characterisation showed that size, surface area and surface charge seem to play a role in the translocation and retention of AuNPs.

\section{Inhalation studies for the evaluation of AuNP-induced lung toxicity}

Inhalation exposure has great advantages for the assessment of human exposure due to the natural path of entry 
of the nanoparticles. A widely used method for these studies is whole-body exposure. A number of these investigations have been carried out using different physical methods of aerosol production: the spark ignition technique for the production of NP aerosols and the evaporation/condensation method. This last method has a good yield and offers accurate control over the deposition parameters. The main disadvantages, compared to the spark ignition generator, are the energy consumption of the furnace and the long heating and cooling times. Although exposure to the whole body represents the condition of physiological exposure and the gold standard of aerosol exposure, the aerosol through an endotracheal intubation/ventilation exposure allows to bypass the extrathoracic airways obtaining a distinct deposition of NPs in the lungs and avoiding further to indicate animal contamination. So, this technique is widely used also for this type of studies.

In a first study, Takenaka et al. (2006) exposed male Wistar-Kyoto rats to ultrafine Au particle aerosol produced with a spark ignition generator in a whole-body chamber to investigate the role of alveolar macrophages in the fate of AuNPs in rat lungs. In this study, aerosol mass concentration, particle number concentration and count median diameter (CMD) were determined. The authors took into considerations the physico-chemical characteristics of AuNPs, such as size, agglomeration and dissolution, to investigate the NP distribution pattern in the lungs by means of ICP-MS and TEM analysis. When the ultrastructure of the AuNPs collected in the air stream from an inhalation chamber was analysed by TEM, most AuNPs in the aerosol were single NPs with diameters between 5 and $8 \mathrm{~nm}$ whereas the agglomerates of NPs showed a mean length ranging from 18 to $34 \mathrm{~nm}$. The authors excluded the dissolution of NPs because their size and shape were identical throughout the experimental period. A large portion of the deposited AuNPs was retained in the lung tissue and found on the surface of the alveolar septum or within vesicles in the cytoplasm of epithelial cells, predominantly in type I cells and also in type II epithelial cells and alveolar macrophages, but not in other regions, such as endothelial cells or the septal interstitium. As already reported for intratracheal instillation studies, AuNPs in alveolar macrophages and type I epithelial cells were processed by endocytotic pathways. Successively, the same group (Takenaka et al. 2012), to further investigate the relationship of alveolar macrophages and inhaled nanoparticles in the lungs and to test the hypothesis that not-agglomerated NPs might not be efficiently eliminated by alveolar macrophages, exposed male WistarKyoto rats for $6 \mathrm{~h}$ in a whole-body inhalation chamber to an aerosol of $14 \mathrm{~nm}$ AuNPs generated by spark discharging. Size distribution and number concentration of AuNP aerosol were determined and NPs were characterised in details in order to determine the shape, the agglomeration state, the composition, the crystalline structure, the specific surface area and surface charge. The authors analysed macrophages in the BAL pellet by TEM to investigate their role in the fate of NPs in alveolar region up to 7 days after exposure. This morphological study represents an in-depth study of a previous quantitative analysis on retention/clearance and systemic translocation of inhaled AuNPs (Takenaka et al. 2006). In this study alveolar macrophages were found to effectively swallow inhaled NPs, however the elimination of NPs from the alveolar lumen was not complete and a significant number of macrophages escape their endocytotic clearance function. Most of macrophages examined on day 0 had internalised AuNPs, but after 7 days the percentage decreased. Individual or agglomerated AuNPs, depending on the time after inhalation, were found within cytoplasmic vesicles. The high fraction of AuNPs found in alveolar macrophages indicates active rather than passive uptake mechanisms. Individual or slightly agglomerated AuNPs were found on day 0 , while on 7 days, most AuNPs were highly agglomerated. The authors suggested that AuNPs, due to their negative surface charge, can bind to elements of the lysosomal system.

In a study on sub-chronic inhalation toxicity, carried out consistently with the Test Guideline 413 from the OECD 2018, seven-week-old male and female Sprague Dawley rats were exposed to AuNPs (about 4-5 nm in diameter) for $6 \mathrm{~h} /$ day, 5 days/week, for 90-days in a whole-body inhalation chamber (Sung et al. 2011). AuNP aerosol was generated by evaporation/ condensation process and characterised in terms of size distribution. Morphological analysis showed AuNPs in single form or agglomerates. In these experiments, different NP concentrations were utilised: low dose $\left(2.36 \times 10^{4}\right.$ particles $\left./ \mathrm{cm}^{3}, 0.04 \mu \mathrm{g} / \mathrm{m}^{3}\right)$, middle dose $\left(2.36 \times 10^{5}\right.$ particles $\left./ \mathrm{cm}^{3}, 0.38 \mu \mathrm{g} / \mathrm{m}^{3}\right)$ and high dose $\left(1.85 \times 10^{6}\right.$ particles $\left./ \mathrm{cm}^{3}, 20.02 \mu \mathrm{g} / \mathrm{m}^{3}\right)$. Tissue Au content was determined after wet digestion by atomic absorption spectrophotometry. Tissue distribution of AuNPs showed a dose-dependent Au accumulation in the lungs and the kidneys with a gender-related 
difference in AuNP content in kidney (female kidneys showed greater gold accumulation than male kidneys). Moreover, this study demonstrated that the lung was the only organ in which dose-related changes occurred in both male and female rats. The histopathologic examination of the lungs identified inflammatory infiltrates of lymphocytes, neutrophils and macrophages. As regards the pulmonary functions, a decrease in tidal and minute volume was observed. Taken together, results from this study indicate that the lungs were the main target organs showing both histopathological and functional changes. It is interesting to note that, in the only study in which male and female animals were used, a gender difference was observed in AuNP target organs.

Another study analysed the effect of inhaled AuNP size on biodistribution of nano-agglomerates in rats using a whole-body inhalation chamber (Balasubramanian et al. 2013). In this research synthesised AuNP suspensions of $7 \mathrm{~nm}$ and $20 \mathrm{~nm}$ were aerosolised by an atomiser aerosol generator and characterised in order to determine NP primary size, size distribution and total number concentrations of airborne agglomerates in the exposure chamber. Male Wistar rats underwent 15-day inhalation exposure (consisting of $6 \mathrm{~h}$ per day, and 5 days per week over 3 weeks) to airborne agglomerates of AuNPs of similar size distribution and number concentration $\left(1 \times 10^{6}\right.$ particles $/ \mathrm{cm}^{3}$ ), but of different primary diameters (7 or $20 \mathrm{~nm}$ ). Results of this study showed that the lungs exhibited high accumulation of $\mathrm{Au}$ for both primary sizes. Inhalation of agglomerates containing $7 \mathrm{~nm}$ AuNPs led to highest deposition by mass concentration in the lungs (followed by different brain regions and other organs such as oesophagus and kidneys). Finally, eight organs/tissues (especially the brain) retained greater mass concentration of $\mathrm{Au}$ after exposure to agglomerates of $7 \mathrm{~nm}$ compared to $20 \mathrm{~nm}$ AuNPs. The authors conclude that the primary size impact on the biodistribution. As previously reported other studies have examined the effects of inhaled AuNPs employing intratracheal instillation of NP solutions (Semmler-Behnke et al. 2008; Jacobsen et al. 2009; Sadauskas et al. 2009; Gosens et al. 2010; Lipka et al. 2010). Although commonly used, this model of exposure may not reflect the actual deposition of inhaled NPs in the lungs, in particular because airborne NPs have a tendency to form agglomerates of different sizes, which influence their deposition in the respiratory tract.

The lung is exposed to pollutants by inhalation and the pulmonary immune system must defend the respiratory tract against harmful agents. In the bronchoalveolar space there are proteins of innate immunity, and, among these, the surfactant protein D (SP-D) plays a chief role in host defence (Marchetti et al. 2015; Jud et al. 2013). Since SP-D can bind to microorganisms for clearance through non-inflammatory pathways, it is likely that SPD may also bind to the inhaled NPs and promote their clearance. Based on these considerations, Schleh et al. 2013a investigated the fate of inhaled AuNPs by analysing also the role of pulmonary surfactant protein D (SP-D). For this study, AuNP aerosol was produced with a spark ignition generator and mass concentration, particle number concentration and CMD were determined. AuNPs in the freshly generated aerosol and collected with an electrostatic TEM sampler were characterised by TEM. The authors showed that the mice were exposed to aerosol mass concentration equal to $1.6 \mathrm{mg} / \mathrm{m}^{3}$ and AuNP number concentration of $2 \times 10^{7}$ particles $/ \mathrm{cm}^{3}$ with a CMD of $22 \mathrm{~nm}$. TEM images showed agglomerated AuNPs with spherical shape. To examine the role of pulmonary SP-D, healthy adult female $\mathrm{C} 57 \mathrm{BL} / 6$ mice were subjected to radioactively labelled AuNP (20 nm) and, before NP exposure, a group of mice received $10 \mu \mathrm{g}$ of dissolved SP-D by intratracheal instillation. Two hours after NP aerosol inhalation in a plethysmograph chamber, the mice were sacrificed, and the biodistribution of AuNPs was investigated. The highest amount of AuNPs was associated with the lung tissue, in agreement with previous intratracheal instillation researches (Lipka et al. 2010), while the instillation of SP-D before the AuNP inhalation did not produce significant effects on their biodistribution. This may be due to different causes. It is possible that the instilled SP-D only increased the physiological pool, without enhancing the activity of the SP-D already present. On the other hand, the measurement time chosen in this study might be too short to allow detection of SP-D modulating effects. The slightly reduced translocation from the lungs to the circulation observed in mice subjected to instillation with SP-D was not significant. However, these data are worth to be studied in more detail, for example by employing longer exposure times.

Concerning inhalation studies for the evaluation of AuNP-induced inflammation, Yin et al. (2019) reported the interaction of sub-100 nm aerosolised NPs with the lungs at the cellular level and the inflammatory responses triggered by their inhalation. The authors characterised synthesised citrate-capped AuNPs and PEG-coated AuNPs with different functional groups 
both in water suspensions and in BAL by DLS, UV-vis, TEM and zeta potential. Moreover, they aerosolised the NPs with an atomiser aerosol generator and continuously monitored the particle number concentration and size distribution of aerosol by CPC and SMPS. Male Balb/c mice between 8 and 12 weeks of age were exposed for $6 \mathrm{~h}$ to an aerosol of AuNPs in whole-body inhalation chambers. For all inhalation duration, the authors maintained the NP concentration at 3 million NPs $/ \mathrm{ml}$. Independently from the functional group, these $\sim 50 \mathrm{~nm} \mathrm{NPs}$ were stable following aerosolisation and incubation in BAL fluid, without extensively crossing the air-blood barrier. This behaviour is not surprising as the overall size of the NPs $(\sim 50 \mathrm{~nm})$ is greater than the limit value for the crossing of the air-blood barrier, allowing the retention of most inhaled NPs inside the lungs to probe their intrapulmonary distribution. Results of this study showed that the different preparations of AuNPs induce different degrees of inflammation, underlining the effect of surface functionality of NP inhaled on the triggered acute inflammatory response. Interestingly, when the authors compared their results in vivo with the results obtained in cell systems, in vitro data revealed the secretion of the same types of pro-inflammatory markers as in vivo studies, but the amount of secretion for each marker was not fully coherent between two systems emphasising the importance of in vivo approaches.

Concerning the relationship between inflammation and AuNP exposure, interesting studies on animal models with inflammatory lung diseases have also been conducted. For example, Geiser et al. (2013) studied the absorption and cellular localisation of inhaled AuNPs in a mouse model of chronic obstructive pulmonary disease (COPD). In this study, female mice (1018 weeks) inhaled the AuNP (about $21 \mathrm{~nm}$ ) aerosol via an endotracheal tube by negative pressure ventilation for $2 \mathrm{~h}$. Different from the whole-body exposure, the endotracheal intubation/ventilation exposure allows to bypass the extrathoracic airways to obtain a distinct deposition of NP in the lungs. Immediately or 1 day after inhalation, both BAL macrophages and whole lung were examined. Also, for this study, NP aerosol, produced by spark generator and heat-treated at $600{ }^{\circ} \mathrm{C}$ to melt the AuNP agglomerates to spherical AuNPs, was continuously monitored in order to determine particle number concentration and size distribution. The AuNP shape was assessed by TEM analysis. Results obtained showed that macrophages contained large (>100 nm)
NP agglomerates, whereas in the lungs, AuNPs were mainly found on the epithelial surface and within surface structures as singlet or small agglomerates $(\leq$ $100 \mathrm{~nm}$ ). Immediately after aerosol inhalation (time 0 ), AuNPs were mainly attached to the lung epithelial surface of COPD mice, whereas in control mice, they were more abundant in macrophages. Twenty-four hours post-aerosol inhalation, the percentage of AuNPs attached to the lung epithelial surface decreased in both groups. Taken together, these data indicate a less efficient macrophage uptake and slow clearance of AuNPs in COPD mice (Geiser et al. 2013). Successively, the same research group analysed the macrophage uptake of AuNPs in a different pathological situation using a mouse models of allergic asthma (Geiser et al. 2014). Mice with COPD were also included in this study. Au NP aerosol was generated as already described (Geiser et al. 2013) and the authors used the characterisation data obtained in the previous study (Geiser et al. 2013). AuNP uptake by macrophages in BAL obtained from mouse models of allergic asthma and COPD challenged by fungi and spores was examined. The results showed that macrophages from sick mice were significantly larger than those from control mice, and as previously reported (Geiser et al. 2013), in mice with COPD, the percentage of macrophages containing AuNPs was lower than that in control mice (Geiser et al. 2014). In the macrophages of all animal groups, the fungal spores were found inside the phagosomes, while AuNPs were visible either with the spores in the phagosomal cavity or, rarely, in the cytoplasm. Moreover, in allergic mice, eosinophils containing AuNPs were observed demonstrating that other inflammatory cells present in the airways can contribute to the internalisation of NPs (Geiser et al. 2014). This study, providing useful information on the intake of AuNPs by airway macrophages in healthy subjects as well as in two suitable inflammatory lung diseases models such as COPD and asthma, will be useful to elucidate the mechanisms responsible for the adverse health effects of inhaled AuNPs.

Other authors have used a "direct" inhalation method instead of the whole-body inhalation chamber. Han et al. (2015b) carried out a study in which male-specific pathogen-free Sprague-Dawley rats were exposed to AuNP aerosol, using a nose-only exposure system. AuNPs were generated by an atomiser and purified air was used as the carrier gas. The aerosol was characterised in order to determine size distribution and particle number concentration by SMPS and CPC. The surface area of NPs 
was calculated by data of aerosol characterisation. Moreover, the NPs in the aerosol were characterised by TEM to determine the size distribution. In this short-term exposure study, animals were exposed to both small AuNPs (about $13 \mathrm{~nm}$ ) and large AuNPs (about $105 \mathrm{~nm}$ ) $6 \mathrm{~h}$ a day for 5 days. The exposure was followed by a recovery period of 1,3 and 28 days in the open air. The results obtained confirm literature data reporting that although both small and large AuNPs deposited mainly in the lungs, small AuNPs were able to move to extrapulmonary organs (liver, spleen, brain and blood) at higher speed than large AuNPs (Kreyling et al. 2014).

These data on the greater translocation capacity of the smaller particles are extremely interesting as they are independent of the method of administration (aerosol or intratracheal instillation).

Another study, employing the intratracheal intubation/ventilation method, investigated the agedependent deposition patterns of inhaled ${ }^{195} \mathrm{Au}$ radiolabeled 20-nm AuNPs in 7-, 14-, 21-, 35-, 60and 90-day-old Wistar-Kyoto rats and the biokinetics fate of the AuNPs in adult rats (60-day-old) (Kreyling et al. 2018). In this study, AuNP aerosol was produced by spark ignition and irradiated in the cyclotron, with protons of about $30 \mathrm{MeV}$ energy in order to produce agglomerated $\left[{ }^{195} \mathrm{Au}\right] \mathrm{AuNPs}$ were treated in a tube furnace at a temperature of $600{ }^{\circ} \mathrm{C}$ to form single spherical NPs of $20 \mathrm{~nm}$. The aerosol was characterised and count median diameter, number concentration and particle volume concentration of aerosol distribution were determined. Results obtained showed that the intratracheal inhalation of AuNPs by negative pressure ventilation caused the deposition of NP preferably in the caudal lungs regardless of the rat age. However, whole deposition in the lung increased with the increasing age due to the augmented lung volume. Regarding the biokinetics studies carried out only in adult rats, it was observed that exposure to NPs resulted in intrathoracic airway deposition and alveolar retention, the latter being the dominant long-term effect (Kreyling et al. 2018).

As AuNPs are able to induce inflammation, in the only study performed in humans, Miller et al. (2017) exposed healthy male non-smoking volunteers aged 18 35 to AuNPs of $5 \mathrm{~nm}$ and $30 \mathrm{~nm}$ for $2 \mathrm{~h}$ via inhalation in a specially built human-controlled exposure chamber in order to assess their potential cardiovascular effects. The authors generated AuNP aerosol of $5 \mathrm{~nm}$ by a commercial spark generator and larger single spherical particles of $30 \mathrm{~nm}$ by extending the residence time in argon via a growth loop to agglomerate particles, followed by thermal fusing of particles. Particle number concentration, size distribution and surface area were monitored. Primary particle size of AuNPs of samples collected on Teflon filters was determined by TEM. Au was detected in the blood and urine samples of human volunteers, with greater levels after inhalation of $5 \mathrm{~nm}$ AuNPs compared to $30 \mathrm{~nm}$. Au, detected within $15 \mathrm{~min}$ to $24 \mathrm{~h}$ after exposure, was still measurable after 3 months. Of particular interest is the observation that the NPs that translocated from the lung to the circulation selectively accumulated at the sites of vascular inflammation. These results were also discussed and further analysed in a subsequent article by the same authors (Raftis and Miller 2019). They exposed, via intratracheal administration, a mice model of atherosclerosis (apolipoprotein E knockout) to purchased AuNP suspensions with sizes in the range 2-200 $\mathrm{nm}$, characterised by TEM and DLS. The authors reported markedly greater translocation for NPs below $10 \mathrm{~nm}$ and preferential accumulation in inflammation-rich vascular lesions (Miller et al. 2017). These results are in agreement with previous data of Jacobsen et al. (2009).

Results from studies utilising whole-body inhalation chambers demonstrated that AuNPs produced with a spark ignition generator are mainly in a single form and a large portion of them is retained in the lung tissue (followed by other organs such as kidneys, brain and oesophagus). AuNPs are internalised within vesicles in the cytoplasm of epithelial cells, predominantly in type I cells and also in macrophages, as already observed in intratracheal instillation studies. Moreover, notwithstanding lungs are the main target organs, a gender-specific difference has been observed in $\mathrm{Au}$ accumulation in the kidney, that resulted greater in female animals. As observed in intratracheal instillation studies, the histopathologic examination of the lungs identified inflammatory infiltrates of lymphocytes, neutrophils and macrophages. However, different preparations of AuNPs induced different degrees of inflammation, underlining the effect of surface functionality of NP inhaled on the triggered acute inflammatory response. Interestingly, in the only study in which in vivo results were compared to in vitro results, the amount of inflammatory markers was not coherent between two systems highlighting the importance of in vivo approaches (Yin et al. 2019).

However, it should be kept in mind that whole-body inhalation studies previously described involve, besides 
Table 5 AuNP toxicity: in vivo studies

\begin{tabular}{|c|c|c|c|c|}
\hline Animal model & Size (nm) & Type of exposure & Main conclusions & Reference \\
\hline Male Wistar-Kyoto rats & $5-8$ & $\begin{array}{l}\text { Intratracheal inhalation of } \\
\text { ultrafine NPs generated } \\
\text { by spark ignition: } \\
\text { whole-body chamber }\end{array}$ & $\begin{array}{l}\text { The particles were single or slightly } \\
\text { agglomerated. Inhaled ultrafine gold } \\
\text { particles in alveolar macrophages and } \\
\text { type I epithelial cells are processed by } \\
\text { endocytotic pathways. }\end{array}$ & $\begin{array}{l}\text { Takenaka et al. } \\
\text { (2006) }\end{array}$ \\
\hline $\begin{array}{l}\text { Female Wistar-Kyoto } \\
\text { rats }\end{array}$ & $\begin{array}{l}1.4 \\
18\end{array}$ & Intratracheal instillation & $\begin{array}{l}1.4 \mathrm{~nm} \text { NPs translocated through the } \\
\text { air-blood barrier in significant } \\
\text { amounts. } 18 \mathrm{~nm} \text { NPs are almost } \\
\text { completely trapped in the lungs. NP } \\
\text { surfaces were modified during translo- } \\
\text { cation. }\end{array}$ & $\begin{array}{l}\text { Semmler-Behnke } \\
\text { et al. (2008) }\end{array}$ \\
\hline Female C57BL mice & $\begin{array}{l}20 \\
40 \\
100\end{array}$ & Intratracheal instillation & $\begin{array}{l}\text { NPs were engulfed by pulmonary } \\
\text { macrophages, only a small part } \\
\text { translocated into systemic circulation, } \\
\text { in a size-dependent manner. }\end{array}$ & $\begin{array}{l}\text { Sadauskas et al. } \\
\text { (2009) }\end{array}$ \\
\hline $\begin{array}{l}\text { Female wild-type } \\
\text { C57BL/6 (C57) and } \\
\text { C57BL/6 apolipopro- } \\
\text { tein E knockout mice }\end{array}$ & 2 & $\begin{array}{l}\text { A single intratracheal } \\
\text { instillation }\end{array}$ & $\begin{array}{l}\text { AuNPs showed inflammatory effects } \\
\text { corresponding to their surface areas. } \\
\text { The pulmonary inflammatory response } \\
\text { was more evident in apolipoprotein E } \\
\text { knockout mice. }\end{array}$ & $\begin{array}{l}\text { Jacobsen et al. } \\
\text { (2009) }\end{array}$ \\
\hline $\begin{array}{l}\text { Female Wistar-Kyoto } \\
\text { rats }\end{array}$ & $\begin{array}{l}5, \text { PEG-modified } \\
5 \text {, plain }\end{array}$ & Intratracheal instillation & $\begin{array}{l}\text { Almost all }(>97 \%) \text { of the NPs instilled } \\
\text { intratracheally remained in the lungs. } \\
\text { PEGylation did not affect translocation } \\
\text { from the lungs. }\end{array}$ & $\begin{array}{l}\text { Lipka et al. } \\
\text { (2010) }\end{array}$ \\
\hline $\begin{array}{l}\text { Male WU } \\
\text { Wistar-derived rats }\end{array}$ & $\begin{array}{l}50 \\
250\end{array}$ & Intratracheal instillation & $\begin{array}{l}\text { Both agglomerated as well as single NPs } \\
\text { were taken up by macrophages. No } \\
\text { differences in pulmonary and systemic } \\
\text { toxicity markers were observed. }\end{array}$ & $\begin{array}{l}\text { Gosens et al. } \\
\quad(2010)\end{array}$ \\
\hline $\begin{array}{l}\text { Male and female } \\
\text { Sprague-Dawley rats }\end{array}$ & $4-5$ & $\begin{array}{l}\text { Whole-body inhalation } \\
\text { chamber }\end{array}$ & $\begin{array}{l}\text { The lung is the only organ in which } \\
\text { dose-related changes in both male and } \\
\text { female rats were observed. } \\
\text { The histological examination of the lungs } \\
\text { identified inflammatory infiltrates of } \\
\text { lymphocytes, neutrophils and } \\
\text { macrophages. }\end{array}$ & Sung et al. (2011) \\
\hline Male Wistar-Kyoto rats & 14 & $\begin{array}{l}\text { Whole-body inhalation } \\
\text { chamber }\end{array}$ & $\begin{array}{l}\text { NPs were internalised in alveolar } \\
\text { macrophages by endocytosis. The } \\
\text { number of NP-containing vesicles and } \\
\text { the size of NP agglomerates were } \\
\text { time-dependent suggesting transloca- } \\
\text { tion and re-arrangement of both NPs } \\
\text { and vesicles in the alveolar macro- } \\
\text { phage. }\end{array}$ & $\begin{array}{l}\text { Takenaka et al. } \\
\text { (2012) }\end{array}$ \\
\hline Male Wistar rats & $\begin{array}{l}7 \\
20\end{array}$ & $\begin{array}{l}\text { Whole-body inhalation } \\
\text { chamber }\end{array}$ & $\begin{array}{l}\text { The highest NP accumulation for both } \\
\text { primary sizes ( } 7 \text { and 20) was in the } \\
\text { lung. } \\
\text { The NP biodistribution is dependent on } \\
\text { primary size of agglomerates: inhaled } \\
\text { agglomerates of 7-nm NPs were dis- } \\
\text { tributed in more organs than that of } \\
\text { 20-nm NPs. }\end{array}$ & $\begin{array}{l}\text { Balasubramanian } \\
\text { et al. (2013) }\end{array}$ \\
\hline Male ICR mice & 20 & Intratracheal instillation & $\begin{array}{l}\text { Instilled colloid NPs were internalised } \\
\text { into the alveolar epithelium at the } \\
\text { air-blood barrier by caveolae-mediated } \\
\text { endocytosis. }\end{array}$ & $\begin{array}{l}\text { Naota et al. } \\
\text { (2013) }\end{array}$ \\
\hline Female C57BL/6 mice & $\begin{array}{l}\text { 20, radioactively } \\
\text { labelled }\end{array}$ & & $\begin{array}{l}\text { Almost all inhaled NPs remained } \\
\text { associated with the lung. Pulmonary }\end{array}$ & $\begin{array}{l}\text { Schleh et al. } \\
\text { (2013a) }\end{array}$ \\
\hline
\end{tabular}


Table 5 (continued)

\begin{tabular}{|c|c|c|c|c|}
\hline Animal model & Size $(n m)$ & Type of exposure & Main conclusions & Reference \\
\hline & & $\begin{array}{l}\text { Intratracheal inhalation by } \\
\text { negative pressure } \\
\text { ventilation }\end{array}$ & $\begin{array}{l}\text { surfactant protein D instillation before } \\
\text { NP inhalation had no influence on their } \\
\text { biodistribution. }\end{array}$ & \\
\hline $\begin{array}{l}\text { Scnn1b-transgenic } \\
\text { (Tg/COPD) mice and } \\
\text { Wt mice }\end{array}$ & 21 & $\begin{array}{l}\text { Intratracheal inhalation by } \\
\text { negative pressure } \\
\text { ventilation }\end{array}$ & $\begin{array}{l}\text { NPs were found mainly attached to the } \\
\text { lung surface of COPD mice, while they } \\
\text { were more abundant in macrophages of } \\
\text { Wt mice. } \\
\text { In COPD mice, the absorption of AuNPs } \\
\text { by macrophages was less efficient } \\
\text { leading to a slow elimination of } \\
\text { particles. }\end{array}$ & $\begin{array}{l}\text { Geiser et al. } \\
\text { (2013) }\end{array}$ \\
\hline $\begin{array}{l}\text { Ovalbumin-sensitised } \\
\text { (allergic asthma), } \\
\text { COPD and Wt mice }\end{array}$ & 20 & $\begin{array}{l}\text { Macrophages in BAL from } \\
\text { sick and control mice } \\
\text { challenged by fungi and } \\
\text { spores }\end{array}$ & $\begin{array}{l}\text { Macrophages of the sick mice were } \\
\text { significantly larger than those of the } \\
\text { control Wt mice. } \\
\text { In mice with allergic asthma, eosinophils } \\
\text { containing AuNPs were observed } \\
\text { demonstrating that inflammatory cells } \\
\text { present on the airways can contribute to } \\
\text { the absorption of NPs. }\end{array}$ & $\begin{array}{l}\text { Geiser et al. } \\
\text { (2014) }\end{array}$ \\
\hline $\begin{array}{l}\text { Female Wistar-Kyoto } \\
\text { rats }\end{array}$ & $\begin{array}{l}1.4,2.8,5,18,80 \\
\quad 200 \\
\text { radioactively } \\
\quad \text { labelled }\end{array}$ & Intratracheal instillation & $\begin{array}{l}\text { After } 24 \mathrm{~h} \text {, most of the inhaled NPs (both } \\
\text { positively and negatively charged) } \\
\text { were revealed in the lungs. } \\
\text { Smaller AuNPs were more likely to cross } \\
\text { the air-blood barrier. } \\
\text { Translocation of NPs with negative } \\
\text { charge was significantly higher } \\
\text { compared to NPs with positive charge. }\end{array}$ & $\begin{array}{l}\text { Kreyling et al. } \\
\text { (2014) }\end{array}$ \\
\hline $\begin{array}{l}\text { Male-specific } \\
\text { pathogen-free } \\
\text { Sprague-Dawley rats }\end{array}$ & $\begin{array}{l}13 \\
105\end{array}$ & Inhalation chamber & $\begin{array}{l}\text { Both small and large NPs were revealed } \\
\text { mainly in rat lungs. } \\
\text { Small NPs were able to move from the } \\
\text { lungs to extrapulmonary organs at a } \\
\text { greater speed than large NPs. }\end{array}$ & Han et al. (2015b) \\
\hline $\begin{array}{l}\text { Healthy male } \\
\text { non-smoking volun- } \\
\text { teers }\end{array}$ & $\begin{array}{l}5 \\
30\end{array}$ & $\begin{array}{l}\text { Human-controlled } \\
\text { exposure chamber }\end{array}$ & $\begin{array}{l}\text { Au was detected in the blood and urine } \\
\text { samples of human volunteers, with } \\
\text { greater levels after inhalation of } 5 \mathrm{~nm} \\
\text { NPs compared to } 30 \mathrm{~nm} \text {. NP } \\
\text { accumulated at the sites of vascular } \\
\text { inflammation. }\end{array}$ & $\begin{array}{l}\text { Miller et al. } \\
\text { (2017), Raftis } \\
\text { and Miller } \\
\text { (2019) }\end{array}$ \\
\hline $\begin{array}{l}\text { Mice model of } \\
\text { atherosclerosis } \\
\text { (apolipoprotein E } \\
\text { knockout) }\end{array}$ & $2-200$ & $\begin{array}{l}\text { Intratracheal } \\
\text { administration }\end{array}$ & $\begin{array}{l}\text { Translocation of NPs smaller than } 10 \mathrm{~nm} \\
\text { was significantly higher compared to } \\
\text { greater NPs. NP accumulation occurred } \\
\text { in inflammation-rich vascular lesions. }\end{array}$ & \\
\hline $\begin{array}{l}\text { Female Wistar-Kyoto } \\
\text { rats of different ages }\end{array}$ & 20 & $\begin{array}{l}\text { Intratracheal inhalation by } \\
\text { negative pressure } \\
\text { ventilation }\end{array}$ & $\begin{array}{l}\text { After inhalation, an anisotropic } \\
\text { deposition, independent of the rat age, } \\
\text { was observed preferably in the caudal } \\
\text { lungs. } \\
\text { Exposure to NPs resulted in intrathoracic } \\
\text { airway deposition and alveolar } \\
\text { retention, the latter being the dominant } \\
\text { long-term effect. }\end{array}$ & $\begin{array}{l}\text { Kreyling et al. } \\
\quad(2018)\end{array}$ \\
\hline Male Balb/c mice & $\begin{array}{l}50 \text { Au@PEGX } \\
\text { NPs (with or } \\
\text { without Cy5.5 } \\
\text { molecules } \\
\text { attached) }\end{array}$ & Inhalation chamber & $\begin{array}{l}\text { Regardless of the functional group, NPs } \\
\text { remained colloidally stable following } \\
\text { aerosolisation and incubation in } \\
\text { bronchoalveolar lavage fluid, without } \\
\text { pronouncedly crossing the air-blood } \\
\text { barrier. }\end{array}$ & Yin et al. (2019) \\
\hline
\end{tabular}


Table 5 (continued)

\begin{tabular}{|c|c|c|c|c|}
\hline Animal model & Size (nm) & Type of exposure & Main conclusions & Reference \\
\hline $\begin{array}{l}\text { Wistar rats with } 3,7 \text { and } \\
\text { 21-day-old pups }\end{array}$ & $\begin{array}{l}5 \\
10\end{array}$ & Intratracheal instillation & $\begin{array}{l}\text { NP translocation from the lungs to the rest } \\
\text { of the body was significantly higher in } \\
\text { infant animals than in adults and } \\
\text { decreased with the age. } \\
\text { In contrast to what was observed for } \\
\text { adults, no difference in the } \\
\text { translocation between } 5 \mathrm{~nm} \text { versus } \\
100 \mathrm{~nm} \text { NPs was observed in infants. }\end{array}$ & $\begin{array}{l}\text { Tsuda et al. } \\
\text { (2019) }\end{array}$ \\
\hline
\end{tabular}

Studies are presented in chronological order in which they were published

inhalation, an additional type of exposure, i.e. the ingestion by licking of particles that accumulate on the skin and the fur. In this context, it is interesting to note that, in a study on the effect of orally administered 10-20 nm AuNPs on the histological structure of the rat lung tissue, pulmonary damage was observed (Elbakary et al. 2018). In this research, adult male albino rats were divided into three groups: two groups treated with AuNPs (one receiving a low dose and another one receiving a high dose every day) and a control group. After 14 days, the mice were sacrificed and the lungs were dissected and examined by optical and electron microscopy. The immunohistochemical examination revealed significant high levels of caspase- 3 activity mainly in the group of rats exposed to the high dose of NPs. This finding is in accordance with the in vitro results by Choi et al. (2012), showing that AuNPs of similar size $(17 \mathrm{~nm})$ led to an increase in apoptosis. The observation by electron microscopy revealed both the thickening of the alveolar wall and the proliferation of pneumocytes type II with degenerative changes. Moreover, inflammatory infiltration and congestion of blood vessels together with the collapse of the alveoli and extravasation of erythrocytes were induced by exposure to AuNPs.

A general conclusion that can be drawn from the reported in vivo studies is that particle translocation from the lungs to other organs is not a significant phenomenon, but when it occurs, the liver often represents the main deposition site of AuNPs. The NP translocation rate is correlated to surface charge, particle size and surface area, being higher for negatively charged and smaller particles (Table 5). Concerning the model of exposure used in the described in vivo studies, some considerations have to be done. For example, intratracheal inhalation is an exposure model that does not reflect the actual deposition of NPs in the lungs as airborne NPs tend to form agglomerates of different sizes that influence their deposition in the lungs (Balasubramanian et al. 2013). On the other hand, the whole-body inhalation system involves other types of exposure such as, in particular, ingestion. As it has been shown that oral administration can cause lung damage (Elbakary et al. 2018), also the exposure by whole-body inhalation chamber is not ideal as it may lead to an overestimation of the damage. The main limitations of in vivo studies are therefore due to the lack of an appropriate model of exposure.

When we compared the effectiveness of intratracheal instillation to aerosol inhalation in order to estimate the dangers of respiratory exposure to AuNPs, we observed that the two different routes of administration can lead to different results. Differences observed in lung response to inhaled compared to instilled NPs were probably due to changes in dose administration times, particle distribution or altered clearance between the two methods. For example, we have observed that in intratracheal instillation studies, the clearance of NPs from the lung is slower and inflammation is greater and lasts longer in the lungs than in inhalation studies. Importantly, the reactivity of the NPs can be different between the different studies also because of the differences in the physico-chemical characteristics due to the production process. In particular, primary particle size, AuNP concentration and purity are important features to check, because these characteristics may diverge from the manufacturer's description.

In summary, in vivo studies demonstrated that, after inhalation, the smallest NPs can overcome the air-blood barrier of the lungs. The translocation of inhaled nanoparticles into the systemic circulation and their accumulation at vascular inflammation sites may explain the link between NPs present in the environment and cardiovascular diseases with important implications for risk management related to the use of ENMs. It is important 
to understand if NPs can cross other barriers such as the blood-brain barrier as there is no doubt that the fate of nanoparticles in the body is critical to understand their health risks. These in vivo toxicity studies, although incomplete, have helped to understand the importance of surface charges and dimensions for an element such as gold, perhaps mistakenly considered "innocent" and are particularly significant in the discussion of the AuNP risk assessment. Based on these considerations, it is therefore extremely important to use more and more in vivo approaches.

\section{Conclusions}

Many in vitro and in vivo studies have been performed to identify the relationship between the physicochemical characteristics of NPs and their biological effects with the aim to assess their safety. Although several toxicological studies and the biodistribution of AuNPs after intravenous, oral and peritoneal administration are available in the literature, there is little information on in vivo inhalation toxicity.

Even if literature data reported in this review are not always consistent, however, in contrast with the idea that AuNPs can be used without worries for human health, they demonstrate that this ENM can be toxic for the respiratory system in various conditions.

Many factors influence the outcome of in vitro studies, in particular: the cell model, the exposure procedure and the physico-chemical properties of AuNPs, such as size and charge. The choice of the cellular system is very important as conflicting results arise from the variability of cell lines used for toxicity assays. Data available in this review seem to indicate the specificity of death response induction in A549 cells compared to other cell lines, such as HepG2 and BHK21 cells (Patra et al. 2007). Conversely, citrate-capped AuNPs were toxic to $\mathrm{CHO}$ cells but not to bronchial BEAS-2B cells (Vetten et al. 2013). Moreover, researches on different respiratory cell lines demonstrated a higher sensitivity of bronchial cells to positively charged AuNPs compared to alveolar cells (Schlinkert et al. 2015). This different sensitivity was also observed for other ENMs (Ursini et al. 2016). Similar AuNP translocation kinetics in alveolar cells of human and murine origin suggests not only the presence of a cell-specific response (Schlinkert et al. 2015) but also the absence of specie-specific mechanisms (Bachler et al. 2015). Results from all these studies are particularly interesting demonstrating that bronchial and alveolar cell models are peculiar and complementary and, therefore, should be both included in this kind of investigations.

As demonstrated in the studies reviewed in this article, size and surface charge modulate NP interaction with the cells. Although in general NP cytotoxicity depends on the size, conflicting literature data have been reported. Focusing on cells of lung origin, some authors observed that AuNP size does not affect cellular uptake and toxicity (Uboldi et al. 2009; Freese et al. 2012), while others found increased cytotoxicity and translocation rates with smaller particles (Liu et al. 2013; Bachler et al. 2015). Moreover, it is still unclear which size of AuNPs induces cellular damage and toxicity in vitro. In fact, some authors observed that AuNPs smaller than $10 \mathrm{~nm}$ penetrating the cell membrane reach the nucleus passing through the nuclear pores (Chithrani et al. 2006; Huo et al. 2014; Pan et al. 2007) and can be genotoxic (Lebedová et al. 2018). Conversely, other researchers reported that bigger AuNPs of 40-50 nm were more toxic to respiratory cells than smaller ones (Choudhury et al. 2013; Chithrani et al. 2006).

Surface coating may change the internalisation pattern of the particles (Zhang et al. 2002). For example, PEG-coated NPs are less prone to agglomerate and less able to interact with proteins. As a consequence, they are not efficiently internalised by the cells. Moreover, PEGcoated NPs can, at some extent, avoid vesicular transport and be found free in the cytoplasm, which is rarely seen with other NPs (Nativo et al. 2008; Brandenberger et al. 2010a). Different from PEG, citrate coating might impair cell viability and proliferation without affecting the AuNP uptake by active endocytosis (Uboldi et al. 2009; Freese et al. 2012). The impact of surface modification on the toxicological potential of AuNPs was also observed in HeLa cells (Niidome et al. 2006), but not in K562 human leukaemic cell line (Connor et al. 2005).

Conclusions that can be drawn from in vitro studies are that positively charged AuNPs enter respiratory cells far more efficiently than negatively charged and neutral particles and smaller NPs induce higher cytotoxicity. Concerning bronchial cells, the extent of cytotoxicity depends on the percentage of positively charged ligands, which is consistent with the observation that positively charged AuNPs depolarise membrane potential and disrupt lipid bilayers of cell membrane (Arvizo et al. 2010). It is important, though, to keep in mind that the surface 
charge can be modified when ENMs come in contact with reactive molecules in the environment, such as serum proteins in media (in vitro experiments) or proteins in physiological fluids (in vivo experiments and accidental or intentional exposure of humans) (Lundqvist et al. 2008; Marchetti et al. 2015). For this reason, ENMs should be characterised regarding their physico-chemical characteristic both before and after suspension in the exposure medium.

Several studies have shown discrepancies between in vitro and in vivo data highlighting the idea that simple in vitro experiments do not always lead to right predictions of in vivo results. For this reason, 3D alveolar models associated to advanced in vitro exposure system have been developed to investigate AuNP uptake and translocation. Of particular importance is the way in which NPs are applied to the cells, in suspension or as aerosols, since it is known that particle deposition in classical submerged conditions occurs mainly by diffusion and does not reproduce deposition in the lung.
Exposure to nebulised NPs at the air-liquid interface should be preferred also because it reduces particle agglomeration and eliminate the variability due to the suspension in different culture media, allowing a better control of the exposure dose (Fröhlich 2018). Studies using this advanced in vitro exposure system confirmed that NPs are internalised by the cells even though a lower toxicity has been observed compared to traditional models. Results from studies utilising these sophisticated in vitro models, that mimic NP behaviour and cell response in a more realistic way, constitute a useful tool for lung toxicity studies. Also, the microenvironment in lungs is an important factor that deserves attention. In particular, in an ideal in vitro model of respiratory exposure to NPs, the influence of pulmonary surfactant should be considered since it could be adsorbed on NPs (Silina et al. 2016; Zhao et al. 2019) and alter their characteristics as well as their toxicity (Jia et al. 2019). Hence, in vitro studies on AuNP toxicity to lung cells should consider reliable models to better reflect the

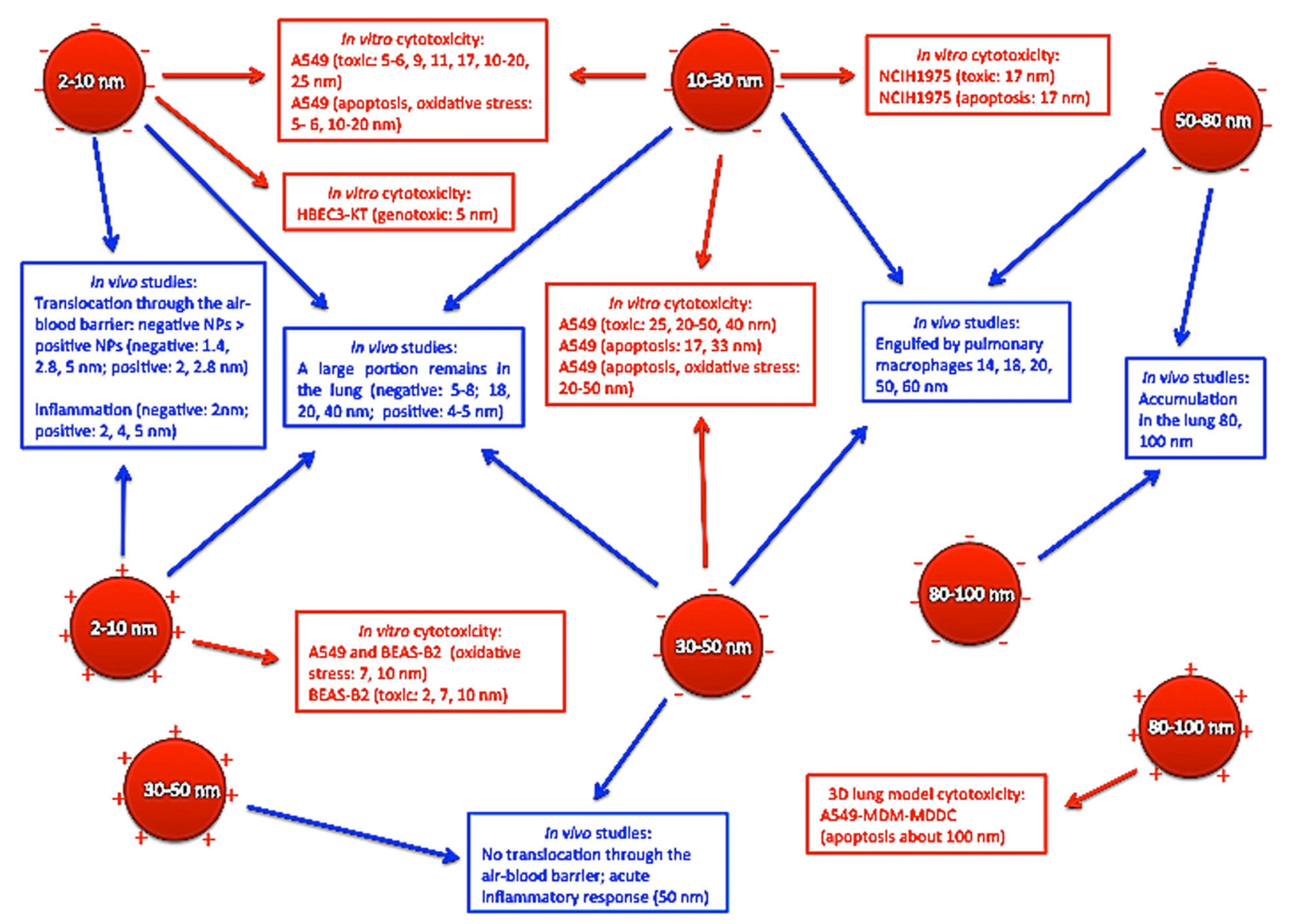

Fig. 6 Schematic representation of the relationship between AuNP characteristics and their toxic effects in vitro and in vivo 
situation in vivo and the role of pulmonary surfactant should not be overlooked.

In vivo studies demonstrated that the highest amount of inhaled AuNPs is associated with the lung tissue and that their translocation across the air-blood barrier depends on NP size, whereas their accumulation in secondary organs depends on specific surface area and charge. Concerning the role of AuNP charge, it has been demonstrated that the percentage of translocation for negative AuNPs is higher than for positive ones. This behaviour is in agreement with in vitro results showing that positively charged AuNPs enter more efficiently bronchial cells and are also cytotoxic. The main limitations of in vivo studies are due to the lack of an appropriate model of exposure. As airborne NPs tend to form agglomerates that influence their deposition in the lungs, intratracheal administration could not reflect the actual NP deposition (Balasubramanian et al. 2013). The whole-body inhalation system may lead to an overestimation of the damage due to ingestion of AuNPs accumulated on the fur. Moreover, the two different routes of administration lead to different results probably because of the different dose administration times, type of sample (suspension or aerosol), particle distribution and NP clearance.

In conclusion, data on the possible consequences at the level of the whole organism of human inhalation exposure to AuNPs are still insufficient and controversial. It is not possible to draw exhaustive conclusions because the available data are not comparable to each other, due to the different exposure conditions, different sample preparations used in the studies, different cell lines and different assays performed. A schematic representation of the relationship between AuNP characteristics and their toxic effects in vitro and in vivo is shown in Fig. 6.

An improved evaluation of the safety of NPs and a better understanding of the mechanisms of cytotoxicity can be obtained only by adopting standardised protocols that include the harmonisation of methods for the preparation of both AuNP suspension and aerosol, their characterisation, as well as the culture conditions, the time exposure and the dose range. Finally, to better understand the interaction with the cell system, it is fundamental to study the changes of AuNPs characteristics in the culture media, such as agglomeration, surface charge and adsorption of serum protein.

Studies are needed that simultaneously analyse the effect of the different AuNP physical parameters using similar experimental exposure conditions in vitro and in vivo. These consistent experimental procedures will help to improve AuNP safety through controlled manipulation of the critical characteristics of this nanomaterial.

Author contributions $\mathrm{BDB}$ and MM acquired, analysed and interpreted the reports present in literature and wrote the manuscript. AR, FI and CF critically revised the manuscript. FS designed the article; acquired, analysed and interpreted the reports present in the literature; and wrote the manuscript. All authors have read, commented and approved the final manuscript.

Funding information This work was supported by the BRICINAIL project through grant ID 53, financing also the AR's research fellowship.

\section{Compliance with ethical standards}

Conflict of interest The authors declare that they have no conflict of interest.

Open Access This article is licensed under a Creative Commons Attribution 4.0 International License, which permits use, sharing, adaptation, distribution and reproduction in any medium or format, as long as you give appropriate credit to the original author(s) and the source, provide a link to the Creative Commons licence, and indicate if changes were made. The images or other third party material in this article are included in the article's Creative Commons licence, unless indicated otherwise in a credit line to the material. If material is not included in the article's Creative Commons licence and your intended use is not permitted by statutory regulation or exceeds the permitted use, you will need to obtain permission directly from the copyright holder. To view a copy of this licence, visit http://creativecommons.org/licenses/by/4.0/.

\section{References}

Albright CD, Jones RT, Hudson EA, Fontana JA, Trump BF, Resau JH (1990) Transformed human bronchial epithelial cells (BEAS-2B) alter the growth and morphology of normal human bronchial epithelial cells in vitro. Cell Biol Toxicol 6: 379-398

Alkilany AM, Nagaria PK, Hexel CR, Shaw TJ, Murphy CJ, Wyatt MD (2009) Cellular uptake and cytotoxicity of gold nanorods: molecular origin of cytotoxicity and surface effects. Small 5:701-708. https://doi.org/10.1002 /smll.200801546

Arnida, Malugin A, Ghandehari H (2010) Cellular uptake and toxicity of gold nanoparticles in prostate cancer cells: a comparative study of rods and spheres. J Appl Toxicol 30: 212-217. https://doi.org/10.1002/jat.1486

Arvizo RR, Miranda OR, Thompson MA, Pabelick CM, Bhattacharya R, Robertson JD, Rotello VM, Prakash YS, 
Mukherjee P (2010) Effect of nanoparticle surface charge at the plasma membrane and beyond. Nano Lett 10:2543-2548. https://doi.org/10.1021/nl101140t

Asbach C, Alexander C, Clavaguera S, Dahmannd D, Dozol H, Faure B, Fierz M, Fontana L, Iavicoli I, Kaminski H, MacCalman L, Meyer-Plath A, Simonow B, van Tongeren M, Todea AM (2017) Review of measurement techniques and methods for assessing personal exposure to airborne nanomaterials in workplaces. Sci Total Environ 603-604: 793-806. https://doi.org/10.1016/j.scitotenv.2017.03.049

Aueviriyavit S, Phummiratch D, Maniratanachote R (2014) Mechanistic study on the biological effects of silver and gold nanoparticles in Caco-2 cells-induction of the Nrf2/HO-1 pathway by high concentrations of silver nanoparticles. Toxicol Lett 224:73-83. https://doi.org/10.1016/j. toxlet.2013.09.020

Bachler G, Losert S, Umehara Y, von Goetz N, RodriguezLorenzo L, Petri-Fink A, Rothen-Rutishauser B, Hungerbuehler K (2015) Translocation of gold nanoparticles across the lung epithelial tissue barrier: combining in vitro and in silico methods to substitute in vivo experiments. Part Fibre Toxicol 12(18):1-18. https://doi.org/10.1186/s12989015-0090-8

Balasubramanian SK, Jittiwat J, Manikandan J, Ong CN, Yu LE, Ong WY (2010) Biodistribution of gold nanoparticles and gene expression changes in the liver and spleen after intravenous administration in rats. Biomaterials 31:2034-2042. https://doi.org/10.1016/j.biomaterials.2009.11.079

Balasubramanian SK, Poh KW, Ong CN, Kreyling WG, Ong WY, $\mathrm{Yu}$ LE (2013) The effect of primary particle size on biodistribution of inhaled gold nano-agglomerates. Biomaterials 34:5439-5452. https://doi.org/10.1016/j. biomaterials.2013.03.080

Bodelón G, Costas C, Pérez-Juste J, Pastoriza-Santos I, LizMarzan L (2017) Gold nanoparticles for regulation of cell function and behavior. Nano Today 13:40-60. https://doi. org/10.1016/j.nantod.2016.12.014

Brandenberger C, Mühlfeld C, Ali Z, Lenz AG, Schmid O, Parak WJ, Gehr P, Rothen-Rutishauser B (2010a) Quantitative evaluation of cellular uptake and trafficking of plain and polyethylene glycol-coated gold nanoparticles. Small 6(15): 1669-1678. https://doi.org/10.1002/smll.201000528

Brandenberger C, Rothen-Rutishauser B, Mühlfeld C, Schmid O, Ferron GA, Maier KL, Gehr P, Lenz AG (2010b) Effects and uptake of gold nanoparticles deposited at the air-liquid interface of a human epithelial airway model. Toxicol Appl Pharmacol 242(1):56-65. https://doi.org/10.1016/j. taap.2009.09.014

Breitner EK, Hussain SM, Comfort KK (2015) The role of biological fluid and dynamic flow in the behavior and cellular interactions of gold nanoparticles. J Nanobiotechnol 13(56): 1-10. https://doi.org/10.1186/s12951-015-0117-1

Brenner SA, Neu-Baker NM, Eastlake AC, Beaucham CC, Geraci C (2016) NIOSH field studies team assessment: worker exposure to aerosolized metal oxide nanoparticles in a semiconductor fabrication facility. J Occup Environ Hyg 13(11): 871-880. https://doi.org/10.1080/15459624.2016.1183015

Brunauer S, Emmett PH, Teller E (1938) Adsorption of gases in multimolecular layers. J Am Chem Soc 60(2):309-319. https://doi.org/10.1021/ja01269a023
Brust M, Walker M, Bethell D, Schiffrin DJ, Whyman RJ (1994) Synthesis of thiol-derivatised gold nanoparticles in a twophase liquid-liquid system. J Chem Soc Chem Commun 7: 801-802. https://doi.org/10.1039/c39940000801

Calzolai L, Gilliland D, Rossi F (2012) Measuring nanoparticles size distribution in food and consumer products: a review. Food Addit Contam Part A Chem Anal Control Expo Risk Assess 29(8):1183-1193. https://doi.org/10.1080 /19440049.2012.689777

Chen L, Wang S, Han C, Cheng Y, Qian L (2015) Performance improvement of inverted polymer solar cells by incorporating $\mathrm{Au}$ and $\mathrm{ZnO}$ nanoparticles bilayer plasmonic nanostructure. Synth Met 209:544-548. https://doi.org/10.1016/j. synthmet.2015.09.016

Chithrani DB (2010) Intracellular uptake, transport, and processing of gold nanostructures. Mol Membr Biol 27(7):299-311. https://doi.org/10.3109/09687688.2010.507787

Chithrani BD, Ghazani AA, Chan WCW (2006) Determining the size and shape dependence of gold nanoparticle uptake into mammalian cells. Nano Lett 6(4):662-668. https://doi. org/10.1021/n1052396o

Chithrani DB, Dunne M, Stewart J, Allen C, Jaffray DA (2010) Cellular uptake and transport of gold nanoparticles incorporated in a liposomal carrier. Nanomedicine 6(1):161-169. https://doi.org/10.1016/j.nano.2009.04.009

Cho EC, Xie J, Wurm PA, Xia Y (2009) Understanding the role of surface charges in cellular adsorption versus internalization by selectively removing gold nanoparticles on the cell surface with a I2/KI etchant. Nano Lett 9(3):1080-1084. https://doi. org/10.1021/nl803487r

Choi SW, Kim WS, Kim JH (2003) Surface modification of functional nanoparticles for controlled drug delivery. J Disper Sci Technol 24(3-2):475-487. https://doi. org/10.1081/DIS-120021803

Choi SY, Jeong S, Jang SH, Park J, Park JH, Ock KS, Lee SY, Joo SW (2012) In vitro toxicity of serum protein-adsorbed citrate-reduced gold nanoparticles in human lung adenocarcinoma cells. Toxicol in Vitro 26(2):229-237. https://doi. org/10.1016/j.tiv.2011.11.016

Choudhury D, Xavier PL, Chaudhari K, John R, Dasgupta AK, Pradeep T, Chakrabarti G (2013) Unprecedented inhibition of tubulin polymerization directed by gold nanoparticles inducing cell cycle arrest and apoptosis. Nanoscale 5(10): 4476-4489. https://doi.org/10.1039/c3nr33891f

Chuang SM, Lee YH, Liang RY, Roam GD, Zeng ZM, Tu HF, Wang SK, Chueh PJ (2013) Extensive evaluations of the cytotoxic effects of gold nanoparticles. Biochim Biophys Acta 1830(10):4960-4973. https://doi.org/10.1016/j. bbagen.2013.06.025

Chugh H, Sood D, Chandra I, Tomar V, Dhawan G, Chandra R (2018) Role of gold and silver nanoparticles in cancer nanomedicine. Artif Cells Nanomed Biotechnol 46(1):12101220. https://doi.org/10.1080/21691401.2018.1449118

Connor EE, Mwamuka J, Gole A, Murphy CJ, Wyatt MD (2005) Gold nanoparticles are taken up by human cells but do not cause acute cytotoxicity. Small 1(3):325-327. https://doi. org/10.1002/smll.200400093

Cruje C, Chithrani BD (2015) Integration of peptides for enhanced uptake of PEGylayed gold nanoparticles. J Nanosci Nanotechnol 15(3):2125-2131. https://doi.org/10.1166 /jnn.2015.10321 
De Berardis B, Civitelli G, Condello M, Lista P, Pozzi R, Arancia G, Meschini S (2010) Exposure to ZnO nanoparticles induces oxidative stress and cytotoxicity in human colon carcinoma cells. Toxicol Appl Pharmacol 246(3):116-127. https://doi. org/10.1016/j.taap.2010.04.012

De Jong WH, Hagens WI, Krystek P, Burger MC, Sips AJ, Geertsma RE (2008) Particle size-dependent organ distribution of gold nanoparticles after intravenous administration. Biomaterials 29(12):1912-1919. https://doi.org/10.1016/j. biomaterials.2007.12.037

Debouttière PJ, Roux S, Vocanson F, Billotey C, Beuf O, FavreRéguillon A, Lin Y, Pellet-Rostaing S, Lamartine R, Perriat P, Tillement O (2006) Design of gold nanoparticles for magnetic resonance imaging. Adv Funct Mater 16(18): 2330-2339. https://doi.org/10.1002/adfm.200600242

Durantie E, Vanhecke D, Rodriguez-Lorenzo L, Delhaes F, Balog S, Septiadi D, Bourquin J, Petri-Fink A, Rothen-Rutishauser B (2017) Biodistribution of single and aggregated gold nanoparticles exposed to the human lung epithelial tissue barrier at the air-liquid interface. Part Fibre Toxicol 14(49):1-14. https://doi.org/10.1186/s12989-017-0231-3

ECHA (2017) Guidance on information requirements and chemical safety assessment. Appendix R7-1 recommendations for nanomaterials applicable to chapter R7a - endpoint specific guidance. http://echa.europa.eu/.

EEC (2012) Communication from the Commission to the European Parliament, the Council and the European Economic and Social Committee: Second Regulatory Review on Nanomaterials https://eurlexeuropaeu/LexUriServ/LexUriServdo?uri=COM:2012 :0572:FIN:en:PDF Accessed 3 October 2012

EFSA (2018) Guidance on risk assessment of the application of nanoscience and nanotechnologies in the food and feed chain: part 1, human and animal health. EFSA J 2018(16): 5327. https://doi.org/10.2903/j.efsa.2018.5327 https://www. efsa.europa.eu/en/efsajournal/pub/5327 Accessed July 2018

Ekstrand-Hammarstrom B, Akfur CM, Andersson PO, Lejon C, Osterlund L, Bucht A (2011) Human primary bronchial epithelial cells respond differently to titanium dioxide nanoparticles than the lung epithelial cell lines A549 and BEAS2B. Nanotoxicology 6(6):1743-5404. https://doi. org/10.3109/17435390.2011.598245

Elbakary RH, Okasha EF, Hassan Ragab AM, Ragab MH (2018) Histological effects of gold nanoparticles on the lung tissue of adult male albino rats. J Microsc Ultrastruct 6(2):116-122. https://doi.org/10.4103/JMAU.JMAU 2518

El-Sherbiny IM, El-Baz NM, Yacoub MH (2015) Inhaled nanoand microparticles for drug delivery. Glob Cardiol Sci Pract 2:1-14. https://doi.org/10.5339/gcsp.2015.2

Flagan RC (2008) Differential mobility analysis of aerosol: a tutorial. KONvA Powder Part J 26:254-268. https://doi. org/10.14356/kona.2008023

Foster KA, Oster CG, Mayer MM, Avery ML, Audus KL (1998) Characterization of the A549 cell line as a type II pulmonary epithelial cell model for drug metabolism. Exp Cell Res 243(2):359-366. https://doi.org/10.1006/excr.1998.4172

Freese C, Uboldi C, Gibson MI, Unger RE, Weksler BB, Romero IA, Couraud PO, Kirkpatrick CJ (2012) Uptake and cytotoxicity of citrate-coated gold nanospheres: comparative studies on human endothelial and epithelial cells. Part Fibre Toxicol 9(23):1-11. https://doi.org/10.1186/1743-8977-9-23
Fröhlich E (2018) Comparison of conventional and advanced in vitro models in the toxicity testing of nanoparticles. Artif Cells Nanomed Biotechnol 46(S2):1091-1107. https://doi. org/10.1080/21691401.2018.1479709

Fröhlich E, Salar-Behzadi S (2014) Toxicological assessment of inhaled nanoparticles: role of in vivo, ex vivo, in vitro, and in silico studies. Int J Mol Sci 15(3):4795-4822. https://doi. org/10.3390/ijms15034795

Fytianos K, Drasler B, Blank F, von Garnier C, Seydoux E, Rodriguez-Lorenzo L, Petri-Fink A, Rothen-Rutishauser B (2016) Current in vitro approaches to assess nanoparticle interactions with lung cells. Nanomedicine 11:2457-2469. https://doi.org/10.2217/nnm-2016-0199

Fytianos K, Chortarea S, Rodriguez-Lorenzo L, Blank F, von Garnier C, Petri-Fink A, Rothen-Rutishauser B (2017) Aerosol delivery of functionalized gold nanoparticles target and activate dendritic cells in a 3D lung cellular model. ACS Nano 11(1):375-383. https://doi.org/10.1021/acsnano.6 b06061

Garcia A, Sparks C, Martinez K, Topmiller JL, Eastlake A, Geraci CL (2017) Nano-metal oxides: exposure and engineering control assessment. J Occup Environ Hyg 14(9):727-737. https://doi.org/10.1080/15459624.2017.1326699

Geiser M, Quaile O, Wenk A, Wigge C, Eigeldinger-Berthou S, Hirn S, Schäffler M, Schleh C, Möller W, Mall MA, Kreyling WG (2013) Cellular uptake and localization of inhaled gold nanoparticles in lungs of mice with chronic obstructive pulmonary disease. Part Fibre Toxicol 10(19):1-10. https://doi. org/10.1186/1743-8977-10-19

Geiser M, Wigge C, Conrad ML, Eigeldinger-Berthou S, Künzi L, Garn H, Renz H, Mall MA (2014) Nanoparticle uptake by airway phagocytes after fungal spore challenge in murine allergic asthma and chronic bronchitis. BMC Pulm Med 14(116):1-13. https://doi.org/10.1186/1471-2466-14-116

George JM, Magogotya M, Vetten MA, Buys AV, Gulumian M (2017) From the cover: an investigation of the genotoxicity and interference of gold nanoparticles in commonly used in vitro mutagenicity and genotoxicity assays. Toxicol Sci 156(1):149-166. https://doi.org/10.1093/toxsci/kfw247

Giard DJ, Aaronson SA, Todaro GJ, Arnstein P, Kersey JH, Dosik H, Parks WP (1973) In vitro cultivation of human tumors: establishment of cell lines derived from a series of solid tumors. J Natl Cancer Inst 51(5):1417-1423. https://doi. org/10.1093/jnci/51.5.1417

Giri K, Yepes LR, Duncan B, Parameswaran PK, Yan B, Jiang Y, Bilska M, Moyano DF, Thompson M, Rotello VM, Prakash YS (2015) Targeting bacterial biofilms via surface engineering of gold nanoparticles. RSC Adv 5(128):105551-105559. https://doi.org/10.1039/C5RA16305F

Glantschnig WJ, Chen SH (1981) Light scattering from water droplets in the geometrical optics approximation. Appl Opt 20(14):2499-2509. https://doi.org/10.1364/AO.20.002499

Gosens I, Post JA, de la Fonteyne LJ, Jansen EH, Geus JW, Cassee FR, de Jong WH (2010) Impact of agglomeration state of nano- and submicron sized gold particles on pulmonary inflammation. Part Fibre Toxicol 7(1):37. https://doi. org/10.1186/1743-8977-7-37

Hainfeld JF, Dilmanian FA, Slatkin DN, Smilowitz HM (2008) Radiotherapy enhancement with gold nanoparticles. J Pharm Pharmacol 60(8):977-985. https://doi.org/10.1211 /jpp.60.8.0005 
Hämeri K, Koponen JK, Aalto PP, Kulmala M (2002) The particle detection efficiency of the TSI-3007 condensation particle counter. J Aerosol Sci 33:1463-1469. https://doi. org/10.1016/S0021-8502(02)00090-3

Hamzawy MA, Abo-Youssef AM, Salem HF, Mohammed SA (2017) Antitumor activity of intratracheal inhalation of temozolomide (Tmz) loaded into gold nanoparticles and/or liposomes against urethane-induced lung cancer in $\mathrm{Balb} / \mathrm{C}$ mice. Drug Deliv 24:599-607. https://doi.org/10.1080 $/ 10717544.2016 .1247924$

Han SG, Lee JS, Ahn K, Kim YS, Kim JK, Lee JH, Shin JH, Jeon KS, Cho WS, Song NW, Gulumian M, Shin BS, Yu IJ (2015a) Size-dependent clearance of gold nanoparticles from lungs of Sprague-Dawley rats after short-term inhalation exposure. Arch Toxicol 89(7):1083-1094. https://doi. org/10.1007/s00204-014-1292-9

Han YD, Park YM, Chun HJ, Yoon HC (2015b) A low-cost optical transducer utilizing common electronics components for the gold nanoparticle based immunosensing application. Sens Actuators B Chem 220:233-242. https://doi. org/10.1016/j.snb.2015.05.081

Hao Y, Altundal Y, Moreau M, Sajo E, Kumar R, Ngwa W (2015) Potential for enhancing external beam radiotherapy for lung cancer using high- $Z$ nanoparticles administered via inhalation. Phys Med Biol 60(18):7035-7043. https://doi. org/10.1088/0031-9155/60/18/7035

Hauck TS, Ghazani AA, Chan WCW (2008) Assessing the effect of surface chemistry on gold nanorod uptake, toxicity, and gene expression in mammalian cells. Small 4(1):153-159. https://doi.org/10.1002/smll.200700217

Hering SV, Stolzenburg MR (2005) A method for particle size amplification by water condensation in a laminar, thermally diffusive flow. Aerosol Sci Technol 39:428-436. https://doi. org/10.1080/027868290953416

Hirn S, Semmler-Behnke M, Schleh C, Wenk A, Lipka J, Schäffler M, Takenaka S, Möller W, Schmid G, Simon U, Kreyling WG (2011) Particle size-dependent and surface charge-dependent biodistribution of gold nanoparticles after intravenous administration. Eur J Pharm Biopharm 77(3): 407-416. https://doi.org/10.1016/j.ejpb.2010.12.029

Holt PG, Schon-Hegrad MA, McMenamin PG (1990) Dendritic cells in the respiratory tract. Int Rev Immunol 6(2-3):139149. https://doi.org/10.3109/08830189009056625

Huang X, Peng X, Wang Y, Wang Y, Shin DM, El-Sayed MA, Nie $S$ (2010) A reexamination of active and passive tumor targeting by using rod-shaped gold nanocrystals and covalently conjugated peptide ligands. ACS Nano 4(10):58875896. https://doi.org/10.1021/nn102055s

Huo S, Jin S, Ma X, Xue X, Yang K, Kumar A, Wang PC, Zhang J, Hu Z, Liang X-J (2014) Ultrasmall gold nanoparticles as carriers for nucleus-based gene therapy due to size-dependent nuclear entry. ACS Nano 8(6):5852-5862. https://doi. org/10.1021/nn5008572

Intra P, Tippayawong N (2007) An overview of aerosol particle sensors for size distribution measurement. Mj Int J Sci Tech 1(2):120-136

Jacobsen NR, Møller P, Jensen KA, Vogel U, Ladefoged O, Loft S, Wallin H (2009) Lung inflammation and genotoxicity following pulmonary exposure to nanoparticles in ApoE-/mice. Part Fibre Toxicol 6:2. https://doi.org/10.1186/17438977-6-2
Jain PK, Huang X, El-Sayed IH, El-Sayed MA (2008) Noble metals on the nanoscale: optical and photothermal properties and some applications in imaging, sensing, biology, and medicine. Acc Chem Res 41(12):1578-1586. https://doi. org/10.1021/ar7002804

Jazayeri MH, Amani H, Pourfatollah AA, Pazoki-Toroudi H, Sedighimoghaddam B (2016) Various methods of gold nanoparticles (GNPs) conjugation to antibodies. Sens Bio-Sens Res 9:17-22. https://doi.org/10.1016/j.sbsr.2016.04.002

Jia J, Yuan X, Peng X, Yan B (2019) Cr(VI)/Pb(2+) are responsible for PM2.5-induced cytotoxicity in A549 cells while pulmonary surfactant alleviates such toxicity. Ecotoxicol Environ Saf 172:152-158. https://doi.org/10.1016/j. ecoenv.2019.01.073

Jud C, Clift MJ, Petri-Fink A, Rothen-Rutishauser B (2013) Nanomaterials and the human lung: what is known and what must be deciphered to realise their potential advantages? Swiss Med Wkly 143:w13758. https://doi.org/10.4414 /smw.2013.13758

Karakoçak BB, Raliya R, Davis JT, Chavalmane S, Wang WN, Ravi N, Biswas P (2016) Biocompatibility of gold nanoparticles in retinal pigment epithelial cell line. Toxicol in Vitro 37:61-69. https://doi.org/10.1016/j.tiv.2016.08.013

Kaur P, Aliru ML, Chadha A, Asea A, Krishnan S (2016) Hyperthermia using nanoparticles. Promises and pitfalls. Int J Hyperth 32(1):76-88. https://doi.org/10.3109 /02656736.2015.1120889

Kirui DK, Rey DA, Batt CA (2010) Gold hybrid nanoparticles for targeted phototherapy and cancer imaging. Nanotechnology 21(10):105105. https://doi.org/10.1088/0957-4484/21/10 $/ 105105$

Kohout C, Santi C, Polito L (2018) Anisotropic gold nanoparticles in biomedical applications. Int Mol Sci 19(11):3385-3414. https://doi.org/10.3390/ijms 19113385

Kreyling WG, Hirn S, Möller W, Schleh C, Wenk A, Celik G, Lipka J, Schäffler M, Haberl N, Johnston BD, Sperling R, Schmid G, Simon U, Parak WJ, Semmler-Behnke M (2014) Air-blood barrier translocation of tracheally instilled gold nanoparticles inversely depends on particle size. ACS Nano 8(1):222-233. https://doi.org/10.1021/nn403256v

Kreyling WG, Möller W, Holzwarth U, Hirn S, Wenk A, Schleh C, Schäffler M, Haberl N, Gibson N, Schittny JC (2018) Age-dependent rat lung deposition patterns of inhaled 20 nanometer gold nanoparticles and their quantitative biokinetics in adult rats. ACS Nano 12:7771-7790. https://doi.org/10.1021/acsnano.8b01826

Kulkarni P, Baroni PA, Killeke K (2012) Aerosol measurement. Principles techniques and applications, Third edn, Wiley, Hoboken

Kumar S, Aaron J, Sokolov K (2008) Directional conjugation of antibodies to nanoparticles for synthesis of multiplexed optical contrast agents with both delivery and targeting moieties. Nat Protoc 3(2):314-320. https://doi.org/10.1038 /nprot.2008.1

Kumar D, Meenan BJ, Dixon D (2012) Glutathione-mediated release of Bodipy ${ }^{\circledR}$ from $P E G$ cofunctionalized gold nanoparticles. Int J Nanomedicine 7:4007-4022. https://doi. org/10.2147/IJN.S33726

Lam ATN, Ganbold EO, Cho KH, Kang D, Joo SW (2014) Raman spectroscopy of gold nanoparticle conjugates of 
cosmetic ingredient kinetin. Vib Spectrosc 73:15-18. https://doi.org/10.1016/j.vibspec.2014.03.010

Lebedová J, Hedberg YS, Odnevall Wallinder I, Karlsson HL (2018) Size-dependent genotoxicity of silver, gold and platinum nanoparticles studied using the mini-gel comet assay and micronucleus scoring with flow cytometry. Mutagenesis 33(1):77-85. https://doi.org/10.1093/mutage/gex027

Lechner J, LaVeck M (1985) A serum-free method for culturing normal human bronchial epithelial cells at clonal density. J Tissue Cult Methods 9:43-48. https://doi.org/10.1007 /BF01797773

Lenz AG, Karg E, Lentner B, Dittrich V, Brandenberger C, Rothen-Rutishauser B, Schulz H, Ferron GA, Schmid O (2009) A dose-controlled system for air-liquid interface cell exposure and application to zinc oxide nanoparticles. Part Fibre Toxicol 6:32. https://doi.org/10.1186/1743-8977-6-32

Liang M, Lin I-C, Whittaker MR, Minchin RF, Monteiro MJ, Toth I (2010) Cellular uptake of densely packed polymer coatings on gold nanoparticles. ACS Nano 4:403-413. https://doi. org/10.1021/nn9011237

Lieber M, Smith B, Szakal A, Nelson-Rees W, Todaro G (1976) A continuous tumor-cell line from a human lung carcinoma with properties of type II alveolar epithelial cells. Int J Cancer 17:62-70. https://doi.org/10.1002/ijc.2910170110

Limbach LK, Wick P, Manser P, Grass RN, Bruinink A, Stark WJ (2007) Exposure of engineered nanoparticles to human lung epithelial cells: influence of chemical composition and catalytic activity on oxidative stress. Environ Sci Technol 41: 4158-4163. https://doi.org/10.1021/es062629t

Lipka J, Semmler-Behnke M, Sperling RA, Wenk A, Takenaka S, Schleh C, Kissel T, Parak WJ, Kreyling WG (2010) Biodistribution of PEG-modified gold nanoparticles following intratracheal instillation and intravenous injection. Biomaterials 31(25):6574-6581. https://doi.org/10.1016/j. biomaterials.2010.05.009

Liu X, Huang N, Li H, Jin Q, Ji J (2013) Surface and size effects on cell interaction of gold nanoparticles with both phagocytic and nonphagocytic cells. Langmuir 29:9138-9148. https://doi.org/10.1021/la401556k

Lohse SE, Murphy CJ (2013) The quest for shape control: a history of gold nanorods synthesis. Chem Mater 25(8): 1250-1261. https://doi.org/10.1021/cm303708p

Löndahl J, Möller W, Pagels JH, Kreyling WG, Swietlicki E, Schmid O (2014) Measurement techniques for respiratory tract deposition of airborne nanoparticles: a critical review. J Aerosol Med Pulm Drug Deliv 27:229-254. https://doi. org/10.1089/jamp.2013.1044

Lundqvist M, Stigler J, Elia G, Lynch I, Cedervall T, Dawson KA (2008) Nanoparticle size and surface properties determine the protein corona with possible implications for biological impacts. Proc Natl Acad Sci U S A 105:14265-14270. https://doi.org/10.1073/pnas.0805135105

Marchetti M, Shaffer MS, Zambianchi M, Chen S, Superti F, Schwander S, Gow A, Zhang JJ, Chung KF, Ryan MP, Porter AE, Tetley TD (2015) Adsorption of surfactant protein D from human respiratory secretions by carbon nanotubes and polystyrene nanoparticles depends on nanomaterial surface modification and size. Philos Trans R Soc Lond Ser B Biol Sci 370:20140038. https://doi.org/10.1098 /rstb.2014.0038
McMurry PH (2000) A review of atmospheric aerosol measurements. Atmos Environ 34:1959-1999. https://doi. org/10.1016/S1352-2310(99)00455-0

Methner M, Hodson L, Dames A, Geraci C (2010) Nanoparticle emission assessment technique (NEAT) for the identification and measurement of potential inhalation exposure to engineered nanomaterial-part B: results from 12 field studies. J Occup Environ Hyg 7(3):163-176. https://doi. org/10.1080/15459620903508066

Miller MR, Shaw CA, Langrish JP (2012) From particles to patients: oxidative stress and the cardiovascular effects of air pollution. Futur Cardiol 8(4):577-602. https://doi. org $/ 10.2217 /$ fca. 12.43

Miller MR, Raftis JB, Langrish JP, McLean SG, Samutrtai P, Connell SP, Wilson S, Vesey AT, Fokkens PHB, Boere AJF, Krystek P, Campbell CJ, Hadoke PWF, Donaldson K, Cassee FR, Newby DE, Duffin R, Mills NL (2017) Inhaled nanoparticles accumulate at sites of vascular disease. ACS Nano 11(5):4542-4552. https://doi.org/10.1021/acsnano.6 b08551

Mironava T, Hadjiargyrou M, Simon M, Jurukovski V, Rafailovich MH (2010) Gold nanoparticles cellular toxicity and recovery: effect of size, concentration and exposure time. Nanotoxicology 4(1):120-137. https://doi.org/10.3109 /17435390903471463

Mittal M, Siddiqui MR, Tran K, Reddy SP, Malik AB (2014) Reactive oxygen species in inflammation and tissue injury. Antioxid Redox Signal 20(7):1126-1167. https://doi. org/10.1089/ars.2012.5149

Naota M, Shimada A, Morita T, Yamamoto Y, Inoue K, Takano H (2013) Caveolae-mediated endocytosis of intratracheally instilled gold colloid nanoparticles at the air-blood barrier in mice. Toxicol Pathol 41(3):487-496. https://doi.org/10.1177 /0192623312457271

Nativo P, Prior IA, Brust M (2008) Uptake and intracellular fate of surface-modified gold nanoparticles. ACS Nano 2:16391644. https://doi.org/10.1021/nn800330a

Ng CT, Tang FMA, Li JJE, Ong C, Yung LLY, Bay BH (2015) Clathrin-mediated endocytosis of gold nanoparticles in vitro. Anat Rec (Hoboken) 298(2):418-427. https://doi. org/10.1002/ar.23051

Nicol JR, Dixon D, Coulter JA (2015) Gold nanoparticle surface functionalization. A necessary requirement in the development of novel nano-therapeutics. Nanomedicine 10(8):13151326. https://doi.org/10.2217/nnm.14.219

Niidome T, Yamagata M, Okamoto Y, Akiyama Y, Takahashi H, Kawano T, Katayama Y, Niidome Y (2006) PEG-modified gold nanorods with a stealth character for in vivo applications. J Control Release 114(3):343-347. https://doi. org/10.1016/j.jconrel.2006.06.017

NIOSH (2012) General safe practices for working with engineered nanomaterials in research laboratories. U.S. Department of Health and Human Services, Centers for Disease Control and Prevention. National Institute for Occupational Safety and Health. Publication no. 2012-147. https://www.cdc. gov/niosh/docs/2012-147/pdfs/2012-147.pdf. Accessed May 2012

Nita R, Trammell SA, Ellis GA, Moore MH, Soto CM, Leary DH, Fontana J, Talebzadeh SF, Knight DA (2016) Kinetic analysis of the hydrolysis of methyl parathion using citratestabilized $10 \mathrm{~nm}$ gold nanoparticles. Chemosphere 144: 
$1916-1919$. https://doi.org/10.1016/j. chemosphere.2015.10.036

Oberdörster G, Maynard A, Donaldson K, Castranova V, Fitzpatrick J, Ausman K, Carter J, Karn B, Kreyling W, Lai D, Olin S, Monteiro-Riviere N, Warheit D, Yang H (2005) Principles for characterising the potential human health effects from exposure to nanomaterials: elements of a screening strategy. Part Fibre Toxicol 2(8):1-35. https://doi. org/10.1186/1743-8977-2-8

OECD (2016a) Series on the safety of manufactured nanomaterials no. 77. Gold nanoparticle occupational exposure assessment in a pilot scale facility. Nanomaterials exposure case study. https://one.oecd. org/document/ENV/JM/MONO\%282016\%2960/en/pdf. Accessed November 2016

OECD (2016b) Series on the safety of manufactured nanomaterials, no. 65. Physical-chemical properties of nanomaterials. Evaluation of methods applied in the OECD-WPMN Testing Programme Organisation for Economic Co-operation and Development. Paris, France https://one.oecd.org/document/ENV/JM/MONO(2016 )7/en/pdf. Accessed February 2016

OECD (2018) OECD guidelines for the testing of chemicals. Test guideline 413. Subchronic inhalation toxicity: 90 day study. OECD, Paris. https://www.oecd.org/env/test-no-413subchronic-inhalation-toxicity-90-day-study9789264070806-en.htm. Accessed June 2018

Ouf FX, Sillon P (2009) Charging efficiency of the electrical low pressure impactor's corona charger: influence of the fractal morphology of nanoparticle aggregates and uncertainty analysis of experimental results. Aerosol Sci Technol 43(7):685698. https://doi.org/10.1080/02786820902878245

Pan Y, Neuss S, Leifert A, Fischler M, Wen F, Simon U, Schmid G, Brandau W, Jahnen-Dechent W (2007) Size dependent cytotoxicity of gold nanoparticles. Small 3:1941-1949. https://doi.org/10.1002/smll.200700378

Pan Y, Leifert A, Ruau D, Neuss S, Bornemann J, Schmid G, Brandau W, Simon U, Jahnen-Dechent W (2009) Gold nanoparticles of diameter $1.4 \mathrm{~nm}$ trigger necrosis by oxidative stress and mitochondrial damage. Small 5:2067-2076. https://doi.org/10.1002/smll.200900466

Park JS, Ahn EY, Park Y (2017) Asymmetric dumbbell-shaped silver nanoparticles and spherical gold nanoparticles greensynthesized by mangosteen (Garcinia mangostana) pericarp waste extracts. Int J Nanomedicine 12:6895-6908. https://doi.org/10.2147/IJN.S140190

Patra HK, Banerjee S, Chaudhuri U, Lahiri P, Dasgupta AK (2007) Cell selective response to gold nanoparticles. Nanomedicine 3(2):111-119. https://doi.org/10.1016/j. nano.2007.03.005

Qiu Y, Liu Y, Wang L, Xu L, Bai R, Ji Y, Wu X, Zhao Y, Li Y, Chen C (2010) Surface chemistry and aspect ratio mediated cellular uptake of Au nanorods. Biomaterials 31(30):76067619. https://doi.org/10.1016/j.biomaterials.2010.06.051

Raftis JB, Miller MR (2019) Nanoparticle translocation and multiorgan toxicity: a particularly small problem. Nano Today 26 : 8-12. https://doi.org/10.1016/j.nantod.2019.03.010

Rambanapasi C, Zeevaart JR, Buntting H, Bester C, Kotze D, Hayeshi R, Grobler A (2016) Bioaccumulation and subchronic toxicity of $14 \mathrm{~nm}$ gold nanoparticles in rats.
Molecules 21(6):763. https://doi.org/10.3390 /molecules21060763

Rayavarapu RG, Petersen W, Hartsuiker L, Chin P, Janssen H, van Leeuwen FWB, Otto C, Manohar S, van Leeuwen TG (2010) In vitro toxicity studies of polymer-coated gold nanorods. Nanotechnology 21(14):145101. https://doi.org/10.1088 /0957-4484/21/14/145101

Roco MC (2011) The long view of nanotechnology development: the National Nanotechnology Initiative at 10 years. J Nanopart Res 13:427-445. https://doi.org/10.1007/s11051$010-0192-z$

Rothen-Rutishauser B, Mühlfeld C, Blank F, Musso C, Gehr P (2007) Translocation of particles and inflammatory responses after exposure to fine particles and nanoparticles in an epithelial airway model. Part Fibre Toxicol 4(9):1-9. https://doi. org/10.1186/1743-8977-4-9

Sadauskas E, Jacobsen NR, Danscher G, Stoltenberg M, Vogel U, Larsen A, Kreyling W, Wallin H (2009) Biodistribution of gold nanoparticles in mouse lung following intratracheal instillation. Chem Cent J 3(16):1-7. https://doi.org/10.1186 /1752-153X-3-16

Saptarshi SR, Duschl A, Lopata AL (2013) Interaction of nanoparticles with proteins: relation to bio-reactivity of the nanoparticle. J Nanobiotechnol 11:26. https://doi.org/10.1186 /1477-3155-11-26

Sathishkumar M, Pavagadhi S, Mahadevan A, Balasubramanian R (2015) Biosynthesis of gold nanoparticles and related cytotoxicity evaluation using A549 cells. Ecotoxicol Environ Saf 114:232-240. https://doi.org/10.1016/j.ecoenv.2014.03.020

Schleh C, Semmler-Behnke M, Lipka J, Wenk A, Hirn S, Schäffler M, Schmid G, Simon U, Kreyling WG (2012) Size and surface charge of gold nanoparticles determine absorption across intestinal barriers and accumulation in secondary target organs after oral administration. Nanotoxicology 6:36-46. https://doi.org/10.3109 $/ 17435390.2011 .552811$

Schleh C, Holzwarth U, Hirn S, Wenk A, Simonelli F, Schäffler M, Möller W, Gibson N, Kreyling WG (2013a) Biodistribution of inhaled gold nanoparticles in mice and the influence of surfactant protein D. J Aerosol Med Pulm Drug Deliv 26(1):24-30. https://doi.org/10.1089 /jamp.2011.0951

Schleh C, Kreyling WG, Lehr CM (2013b) Pulmonary surfactant is indispensable in order to simulate the in vivo situation. Part Fibre Toxicol 10:6. https://doi.org/10.1186/1743-8977-10-6

Schlinkert P, Casals E, Boyles M, Tischler U, Hornig E, Tran N, Zhao J, Himly M, Riediker M, Oostingh GJ, Puntes V, Duschl A (2015) The oxidative potential of differently charged silver and gold nanoparticles on three human lung epithelial cell types. J Nanobiotechnol 13:1. https://doi. org/10.1186/s12951-014-0062-4

Semmler-Behnke M, Kreyling WG, Lipka J, Fertsch S, Wenk A, Takenaka S, Schmid G, Brandau W (2008) Biodistribution of 1.4- and 18-nm gold particles in rats. Small 4(12):21082111. https://doi.org/10.1002/smll.200800922

Senut MC, Zhang Y, Liu F, Sen A, Ruden DM, Mao G (2016) Size-dependent toxicity of gold nanoparticles on human embryonic stem cells and their neural derivatives. Small 12(5): 631-646. https://doi.org/10.1002/smll.201502346

Shi JP, Harrison RM, Evans DE (2001) Comparison of ambient particle surface area measurement by epiphaniometer and 
SMPS/APS. Atmos Environ 35:6193-6200. https://doi. org/10.1016/S1352-2310(01)00382-X

Silina YE, Welck J, Kraegeloh A, Koch M, Fink-Straube C (2016) Interactions between DPPC as a component of lung surfactant and amorphous silica nanoparticles investigated by HILIC-ESI-MS. J Chromatogr B Analyt Technol Biomed Life Sci 1029-1030:222-229. https://doi.org/10.1016/j. jchromb.2016.07.014

Smith E, Dent G (2005) Modern Raman spectroscopy: a practical approach. Wiley, Chichester

Sonavane G, Tomoda K, Makino K (2008) Biodistribution of colloidal gold nanoparticles after intravenous administration: effect of particle size. Colloids Surf B Biointerfaces 66(2): 274-280. https://doi.org/10.1016/j.colsurfb.2008.07.004

Sung JH, Ji JH, Park JD, Song MY, Song KS, Ryu HR, Yoon JU, Jeon KS, Jeong J, Han BS, Chung YH, Chang HK, Lee JH, Kim DW, Kelman BJ, Yu IJ (2011) Subchronic inhalation toxicity of gold nanoparticles. Part Fibre Toxicol 8(16):1-18. https://doi.org/10.1186/1743-8977-8-16

Sylvestre JP, Poulin S, Kabashin AV, Sacher E, Meunier M, Luong JHT (2004) Surface chemistry of gold nanoparticles produced by laser ablation in aqueous media. J Phys Chem B 108(43):16864-16869. https://doi.org/10.1021/jp047134+

Takenaka S, Karg E, Kreyling WG, Lentner B, Möller W, Behnke-Semmler M, Jennen L, Walch A, Michalke B, Schramel P, Heyder J, Schulz H (2006) Distribution pattern of inhaled ultrafine gold particles in the rat lung. Inhal Toxicol 18(10):733-740. https://doi.org/10.1080 /08958370600748281

Takenaka S, Möller W, Semmler-Behnke M, Karg E, Wenk A, Schmid O, Stoeger T, Jennen L, Aichler M, Walch A, Pokhrel S, Mädler L, Eickelberg O, Kreyling WG (2012) Efficient internalization and intracellular translocation of inhaled gold nanoparticles in rat alveolar macrophages. Nanomedicine (Lond) 7(6):855-865. https://doi. $\operatorname{org} / 10.2217 / \mathrm{nnm} .11 .152$

Tang Y, Shen Y, Huang L, Lv G, Lei C, Fan X, Lin F, Zhang Y, Wu L, Yang Y (2015) In vitro cytotoxicity of gold nanorods in A549 cells. Environ Toxicol Pharmacol 39(2):871-878. https://doi.org/10.1016/j.etap.2015.02.003

Taylor U, Klein S, Petersen S, Kues W, Barcikowski S, Rath D (2010) Nonendosomal cellular uptake of ligand-free, positively charged gold nanoparticles. Cytometry A 77(5):439446. https://doi.org/10.1002/cyto.a.20846

Techane SD, Gamble LJ, Castner DG (2011) X-ray photoelectron spectroscopy characterization of gold nanoparticles functionalized with amine-terminated alkanethiols. Biointerphases 6(3):98-104. https://doi.org/10.1116/1.3622481

Tsuda A, Donaghey TC, Konduru NV, Pyrgiotakis G, Van Winkle LS, Zhang Z, Edwards P, Bustamante JM, Brain JD, Demokritou P (2019) Age-dependent translocation of gold nanoparticles across the air-blood barrier. ACS Nano 13(9): 10095-10102. https://doi.org/10.1021/acsnano.9b03019

Turkevich J, Stevenson PC, Hillier J (1951) A study of the nucleation and growth process in the synthesis of colloidal gold. Discuss Faraday Soc 11:55-75

Uboldi C, Bonacchi D, Lorenzi G, Hermanns MI, Pohl C, Baldi G, Unger RE, Kirkpatrick CJ (2009) Gold nanoparticles induce cytotoxicity in the alveolar type-II cell lines A549 and NCIH441. Part Fibre Toxicol 6(18):1-12. https://doi. org/10.1186/1743-8977-6-18
Ursini CL, Maiello R, Ciervo A, Fresegna AM, Buresti G, Superti F, Marchetti M, Iavicoli S, Cavallo D (2016) Evaluation of uptake, cytotoxicity and inflammatory effects in respiratory cells exposed to pristine and $-\mathrm{OH}$ and $-\mathrm{COOH}$ functionalized multi-wall carbon nanotubes. J Appl Toxicol 36(3):394-403. https://doi.org/10.1002/jat.3228

van Broekhuizen P, van Broekhuizen F, Cornelissen R, Reijnders L (2012) Workplace exposure to nanoparticles and the application of provisional nanoreference values in times of uncertain risks. J Nanopart Res 14:770. https://doi.org/10.1007 /s11051-012-0770-3

Vance ME, Kuiken T, Vejerano EP, McGinnis SP, Hochella MF Jr, Rejeski D, Hull MS (2015) Nanotechnology in the real world: redeveloping the nanomaterial consumer products inventory. Beilstein J Nanotechnol 6:1769-1780. https://doi.org/10.3762/bjnano.6.181

Vetten M, Gulumian M (2019) Differences in uptake of $14 \mathrm{~nm}$ PEG-liganded gold nanoparticles into BEAS-2B cells is dependent on their functional groups. Toxicol Appl Pharmacol 363:131-141. https://doi.org/10.1016/j.taap.2018.11.014

Vetten MA, Tlotleng N, Tanner Rascher D, Skepu A, Keter FK, Boodhia K, Koekemoer LA, Andraos C, Tshikhudo R, Gulumian M (2013) Label-free in vitro toxicity and uptake assessment of citrate stabilised gold nanoparticles in three cell lines. Part Fibre Toxicol 10(50):1-15. https://doi. org/10.1186/1743-8977-10-50

Vines JB, Yoon JH, Ryu NE, Lim DJ, Park H (2019) Gold nanoparticles for photothermal cancer therapy. Front Chem 7:167. https://doi.org/10.3389/fchem.2019.00167

Wan J, Wang JH, Liu T, Xie Z, Yu XF, Lia W (2015) Surface chemistry but not aspect ratio mediates the biological toxicity of gold nanorods in vitro and in vivo. Sci Rep 5:11398. https://doi.org/10.1038/srep11398

Wang Y, Black KC, Luehmann H, Li W, Zhang Y, Cai X, Wan D, Liu SY, Li M, Kim P, Li ZY, Wang LV, Liu Y, Xia Y (2013) Comparison study of gold nanohexapods, nanorods, and nanocages for photothermal cancer treatment. ACS Nano 7: 2068-2077. https://doi.org/10.1021/nn304332s

Wang Z, Xie D, Liu H, Bao Z, Wang Y (2016) Toxicity assessment of precise engineered gold nanoparticles with different shapes in zebrafish embryos. RSC Adv 6:33009-33013. https://doi.org/10.1039/C6RA00632A

Wikenheiser KA, Vorbroker DK, Rice WR, Clark JC, Bachurski CJ, Oie HK, Whitsett JA (1993) Production of immortalized distal respiratory epithelial cell lines from surfactant protein $\mathrm{C} /$ simian virus 40 large tumor antigen transgenic mice. Proc Natl Acad Sci U S A 90:11029-11033. https://doi. org/10.1073/pnas.90.23.11029

Xia Q, Li H, Liu Y, Zhang S, Feng Q, Xiao K (2017) The effect of particle size on the genotoxicity of gold nanoparticles. J Biomed Mater Res A 105:710-719. https://doi.org/10.1002 /jbm.a.35944

Yah CS, Simate GS, Iyuke SE (2012) Nanoparticles toxicity and their routes of exposures. Pak J Pharm Sci 25:477-491

Yin B, Chan CKW, Liu S, Hong H, Wong SHD, Lee LKC, Ho LWC, Zhang L, Leung KC, Choi PC, Bian L, Tian XY, Chan MN, Choi CHJ (2019) Intrapulmonary cellular-level distribution of inhaled nanoparticles with defined functional groups and its correlations with protein corona and inflammatory response. ACS Nano 13(12):14048-14069. https://doi.org/10.1021/acsnano.9b06424 
Yokel RA, Macphail RC (2011) Engineered nanomaterials: exposures, hazards, and risk prevention. J Occup Med Toxicol 6: 7. https://doi.org/10.1186/1745-6673-6-7

Zhang Y, Kohler N, Zhang M (2002) Surface modification of superparamagnetic magnetite nanoparticles and their intracellular uptake. Biomaterials 23(7):1553-1561. https://doi. org/10.1016/s0142-9612(01)00267-8

Zhang XD, Wu HY, Wu D, Wang YY, Chang JH, Zhai ZB, Meng AM, Liu PX, Zhang LA, Fan FY (2010) Toxicologic effects of gold nanoparticles in vivo by different administration routes. Int J Nanomedicine 5:771-781. https://doi. org/10.2147/IJN.S8428

Zhao P, Li N, Astruc D (2013) State of the art in gold nanoparticle synthesis. Coord Chem Rev 257:638-665. https://doi. org/10.1016/j.ccr.2012.09.002
Zhao Q, Li Y, Chai X, Geng Y, Cao Y, Xu L, Zhang L, Huang J, Ning P, Tian S (2019) Interaction of pulmonary surfactant with silica and polycyclic aromatic hydrocarbons: implications for respiratory health. Chemosphere 222:603-610. https://doi.org/10.1016/j.chemosphere.2019.02.002

Zimmermann E, Derrough S, Locatelli D, Durand C, Fromaget JL, Lefranc E, Ravanel X, Garrione J (2012) Results of potential exposure assessments during the maintenance and cleanout of deposition equipment. J Nanopart Res 14:1209. https://doi.org/10.1007/s11051-012-1209-6

Publisher's note Springer Nature remains neutral with regard to jurisdictional claims in published maps and institutional affiliations. 